World Journal of Advanced Research and Reviews
eISSN: 2581-9615 CODEN (USA): WJARAI
Cross Ref DOI: $10.30574 /$ wjarr
JuRR
Journal homepage: https://wjarr.com/
Research and
Reviews

(REVIEW ARTICLE)

Check for updates

\title{
Review for metal and organocatalysis of heterocyclic C-H functionalization
}

\author{
Ahmed A. El-Sayed *, Nahid Y. Khaireldin and Eman A. El-Hefny \\ National Research Centre, Photochemistry Department, Industrial Chemical Division, Cairo, Egypt.
}

World Journal of Advanced Research and Reviews, 2021, 09(01), 001-030

Publication history: Received on 01 October 2020; revised on 21 December 2020; accepted on 25 December 2020

Article DOI: https://doi.org/10.30574/wjarr.2021.9.1.0071

\begin{abstract}
Over the last few decades, significant efforts have been put forth towards the $\mathrm{C}-\mathrm{H}$ bond group functionalization by transition-metalcatalysis and organocatalysis. Several efficient strategies to convert C-H bond to other groups C-C, C-N, $\mathrm{C}-\mathrm{O}$ bonds have been implemented. The most attractive $\mathrm{C}-\mathrm{H}$ bond functionalization was the $\mathrm{C}-\mathrm{H}$ heterocyclic compounds activation that is practical method in organic synthesis. The new $\mathrm{C}-\mathrm{C}, \mathrm{C}-\mathrm{N}$ and $\mathrm{C}-\mathrm{O}$ bond as formed from the $\mathrm{C}-\mathrm{H}$ bond activation by two diverse ways metal catalysis and/or organocatalysis. The most important is the synthesis of new bioactive heterocyclic compounds by easy and less expensive materials. In this review, we will cover most of the syntheses of heterocyclic derivatives by the functionalization of $\mathrm{C}-\mathrm{H}$ bond in metal and organocatalytic reagents.
\end{abstract}

Keywords: Heterocyclic; C-H activation; Metal catalysis; C-H activation; C-H activation organocatalysis.

\section{Introduction}

Direct $\mathrm{C}-\mathrm{H}$ bond transformation of saturated alkanes or hydrocarbons sp3 hybridized has become a challenging goal in modern synthetic organic chemistry. This functionalization draws the attention of chemists for almost a century [1-3]. $\mathrm{C}-\mathrm{H}$ activation was one of the importance's in synthetic organic chemistry in either academic or industry in the last few decades [1-8]. Several methods exist for synthesis and formation of $\mathrm{C}-\mathrm{C}, \mathrm{C}-\mathrm{N}$ and $\mathrm{C}-\mathrm{O}$ bonds possessing functionalization of sp3 C-H bond. The functionalization of inactive $\mathrm{C}-\mathrm{H}$ bond sp3 hybridized start by the $\mathrm{C}-\mathrm{H}$ free radical activation of methane to methanol using high temperature and expensive material [7]. The reaction of benzene with mercury (II) acetate was report as the first metal catalyst of the C-H activation by Otto Dimroth in 1902 [4]. The activation of $\mathrm{C}-\mathrm{H}$ bond to synthesis new of heterocyclic compounds containing nitrogen atoms is important in many pharmaceutical and biologically active compounds. However, the organic synthetic researchers have new strategy in the synthetic rout of organic compounds from the functionalization of $\mathrm{C}-\mathrm{H}$ bond. Most reports focus on the $\mathrm{sp}^{3}, \mathrm{sp}^{2} \mathrm{C}-\mathrm{H}$ bond activation, by using quantities of transition metal activation or transition metal-catalysis and organocatalysis reagents. In the past few decades, many methods have been developed to directly functionalize $\mathrm{C}-\mathrm{H}$ bonds, often involving the late transition metals or noble metals [9-22]. C-H activation mainly achieve through four metal-mediated pathways: oxidative addition, electrophilic substitution, $\sigma$-bond metathesis and metal-associat ccurre/nitrene/oxo insertion [23-26]. The modern methods focus on the organocatalytic reagents (Metal free-catalysis) in the $\mathrm{C}-\mathrm{H}$ bond activation [27-35]. Moreover, the organocatalytic methods are most important, because methods involving such metalcatalysts are often expensive, another advantage must be the requirement to purify the organic compounds from metallic impurities from the products could be avoided; an important issue in the synthesis of pharmaceutical compounds (Figure 1). Furthermore, the $\mathrm{C}-\mathrm{H}$ functionalization of sp3 $\mathrm{C}-\mathrm{H}$ hybridized by organic complexes under visible light activation has a powerful tool in redox reaction chemistry (Figure 2) [36-46].

\footnotetext{
${ }^{*}$ Corresponding author: Ahmed Ali El-Sayed

National Research Centre, Photochemistry Department, Industrial Chemical Division, Cairo, Egypt.

Department of Photochemistry, Industrial Chemical Division, National Research Centre, P.O. Box: 12611, City, Cairo. 


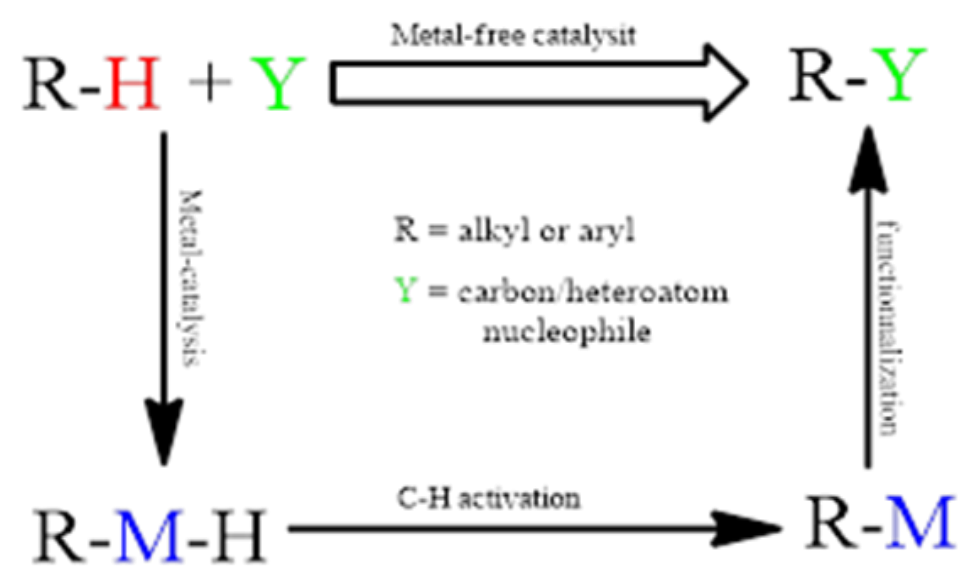

Figure 1 Metal and organocatalytic activation

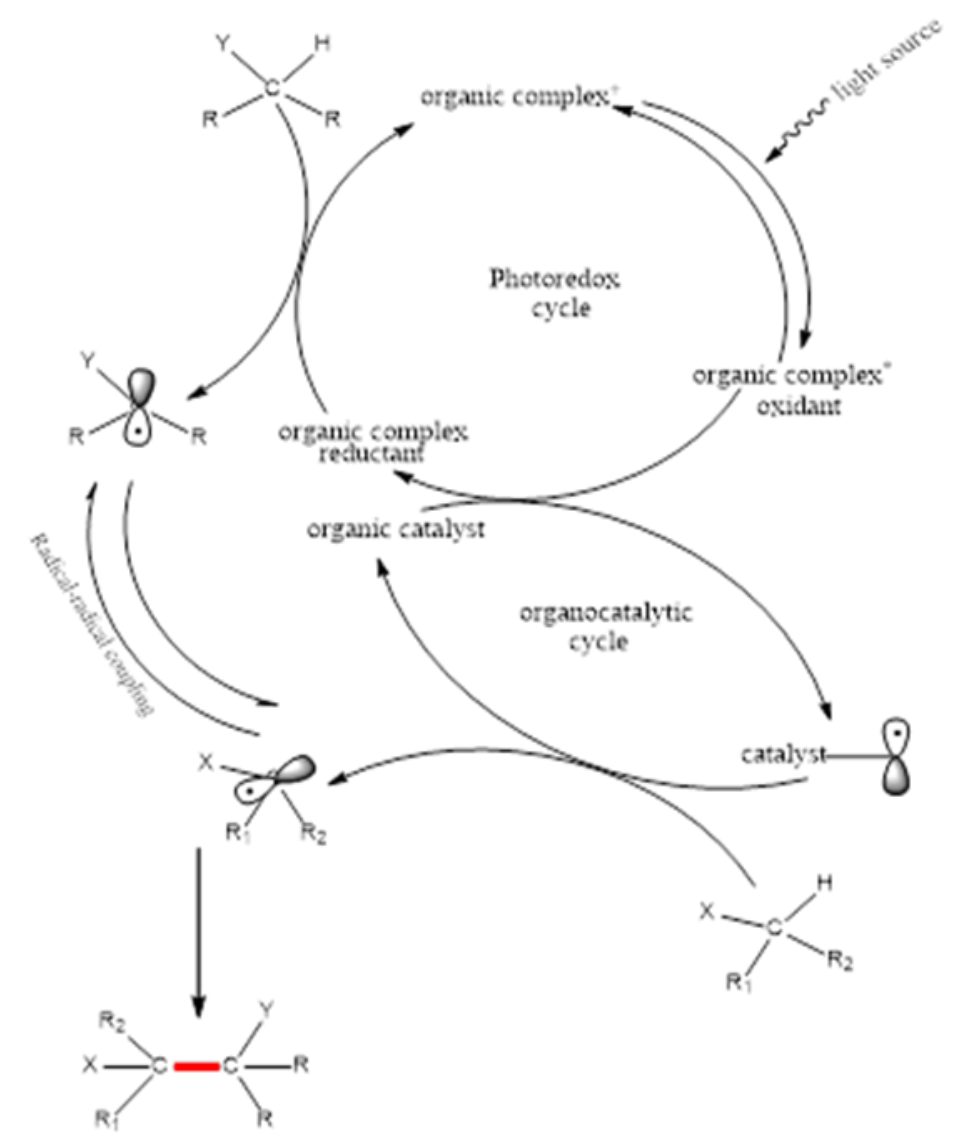

Figure 2 Visible Light Activation Mechanism

\section{Direct c-h bond functionalization by means of transition metal-catalysis}

In few past decades, the transition metal complexes were used in the activation of alkanes $\mathrm{C}-\mathrm{H}$ bond in $\mathrm{C}-\mathrm{H}$ oxidative addition [47], electrophilic cleavage of $\mathrm{C}-\mathrm{H}$ bonds, and oxidation [48-49]. John F. H. and coworkers explained the transition metal complex reactions in the activation of $\mathrm{C}-\mathrm{H}$ alkanes by using of simple transition-metal complexes of $\mathrm{Cp} * \mathrm{M}(\mathrm{CO}), \mathrm{BR},[\mathrm{Cp} * \mathrm{C}(\mathrm{CH})]$ containing an electrophilic, covalently bound main-group ligand react with alkanes. The reactions produce alkylboronate esters, which are common reagents in organic synthesis [11]. (Scheme 1) 


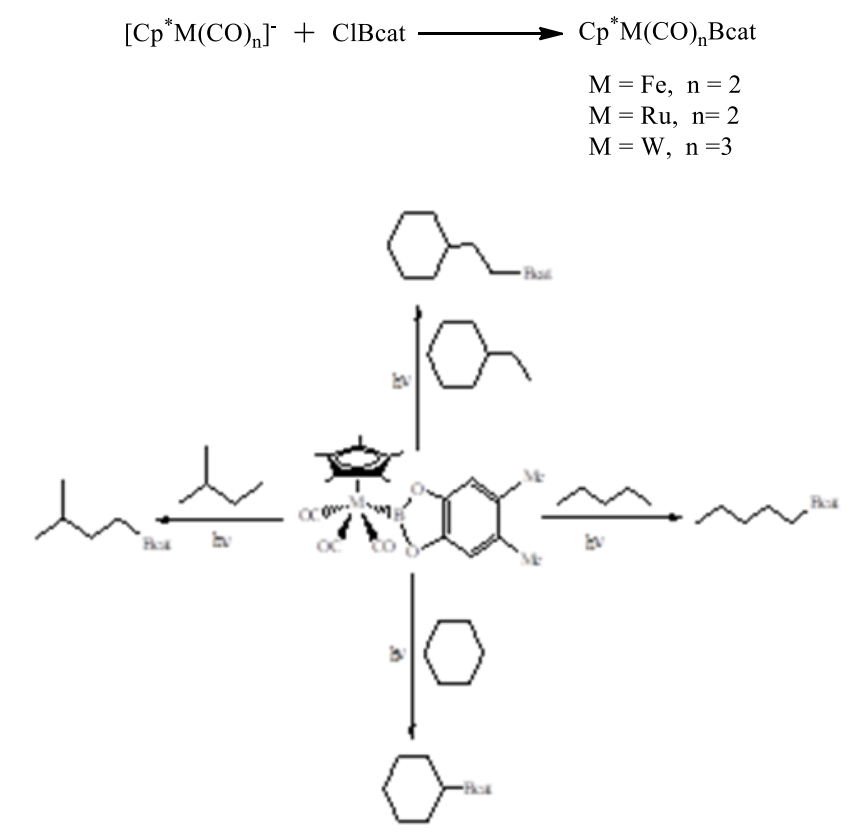

\subsection{C-H bond oxidation}

$\mathrm{Cu}, \mathrm{Pd} 0, \mathrm{PdII}, \mathrm{PdIV}, \mathrm{Ru}$ and Ir were the famous metal catalysis. This metal catalysis used in the C-H bond activation [5052]. The oxidation of $\mathrm{C}-\mathrm{H}$ bond was used $\mathrm{Cu}$ (II) - catalyzed under air $\mathrm{O}_{2}$ condition. The activation of $\mathrm{C}-\mathrm{H}$ bond using $\mathrm{Cu}$ $(\mathrm{OAc})_{2}$ in presence of $\mathrm{H}_{2} \mathrm{O}$ and $\mathrm{O}_{2}$ could be direct oxidation of aryl $\mathrm{C}-\mathrm{H}$ bond 6 which direct into ortho-position 7. Furthermore, the initial use of other copper sources, $\mathrm{CuX}_{2}$, or a combination of $\mathrm{Cu}(\mathrm{OAc})_{2}$ and nucleophilic anions could be equally effective [50-52]. (Scheme 2)

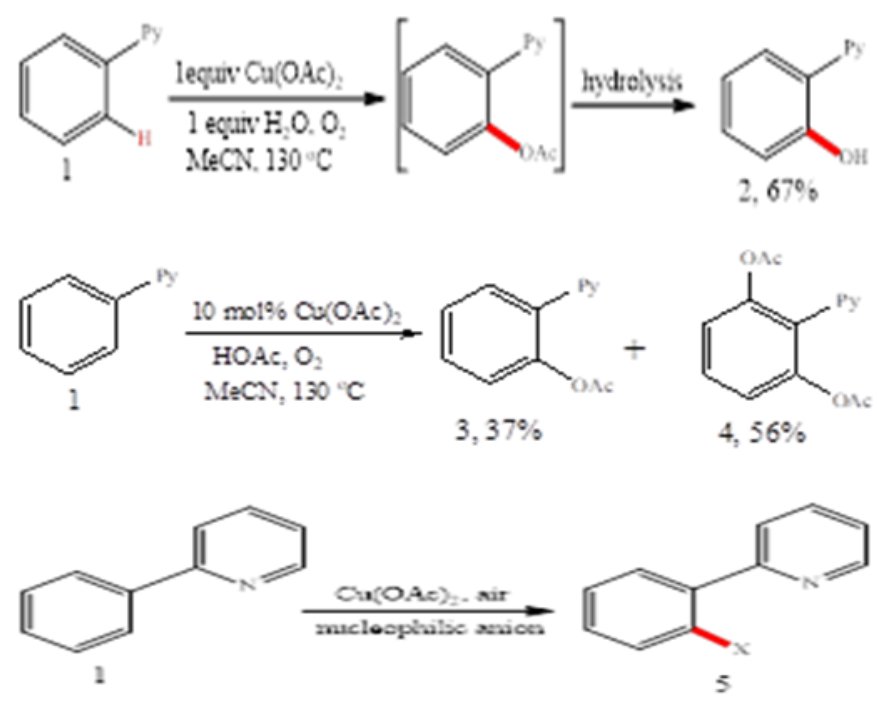

The low-temperature oxidation of methane, ethane, and butane are used in the high catalytic bimetallic system copper chloride and metallic palladium to have methanol [54,55]. The intermolecular oxidation of $\mathrm{C}-\mathrm{H}$ bond by using coppercatalysis, Hideko and coworkers were explained the aryl intermolecular oxidation of $\mathrm{C}-\mathrm{H}$ bond by using of $\mathrm{Cu}(\mathrm{Otf})_{2}(20$ mol\%) at 140 xylene under an atmosphere of $\mathrm{O}_{2}$. The oxidation of $\mathrm{N}$-phenylbenzamide derivatives 6 by using $\mathrm{Cu}(\mathrm{Otf})_{2}$ under oxygen condition to have benzooxazole 12 derivatives in high yield [53]. On the other hand, the intermolecular oxidation also can be done by the $\mathrm{CuBr}_{2}$ is carried out in presence of $\mathrm{Cs}_{2} \mathrm{CO}_{3}$ and $\mathrm{PivOH}$ are employed as additives under an air atmosphere [54,55]. (Scheme 3) 

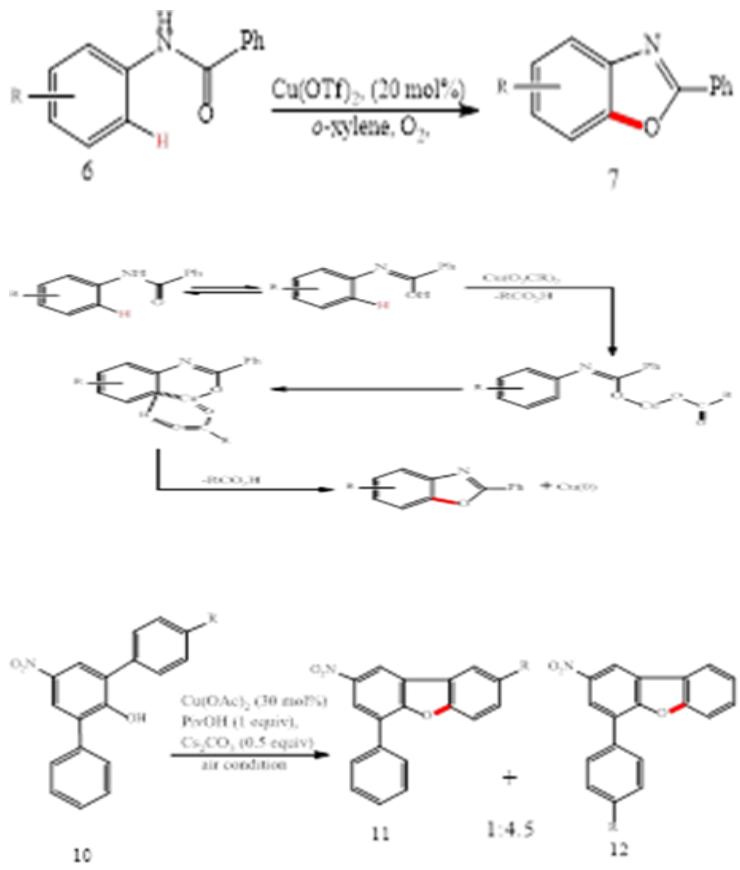

(Scheme 3)

Most oxidation of the inactive $\mathrm{Sp}^{3} \mathrm{C}-\mathrm{H}$ such as alcohols, ketones, aldehydes and carboxylic acids was created by quantities of oxyanions of toxic metals like $\mathrm{Mn}(\mathrm{VII})$ and $\mathrm{Cr}(\mathrm{VI}),[56,57]$, the amount of the toxic waste of these oxidants products and limitations on their use by new legislation [58] has prompted scientists to search for more sustainable oxidation methods. In the early article Bert $\mathrm{U}$. W. and co-workers used $\mathrm{Cu}$ and $\mathrm{Fe}$ catalysis $\left(\mathrm{CuI}\right.$ and $\left.\mathrm{FeCl}_{2} \cdot 4 \mathrm{H}_{2} \mathrm{O}\right)$ as oxidant the regioisomeric 4-benzylpyridines using $\mathrm{FeCl}_{2} \cdot 4 \mathrm{H}_{2} \mathrm{O}$ as the catalyst. Under the standard conditions previously were developed for 2-benzylpyridines these substrates smoothly oxidized give the corresponding ketones in moderate to good yields [59].

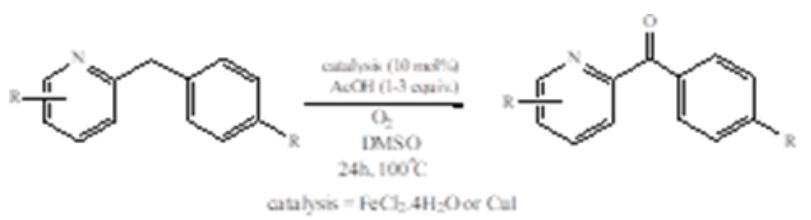

Qiang Zhu and coworkers used the copper iodide in synthesis of 2- or 4-iododibenzofurans in the presence of oxygen at $140^{\circ} \mathrm{C} 24 \mathrm{~h}$; and PivOH in good to moderate yields [60].

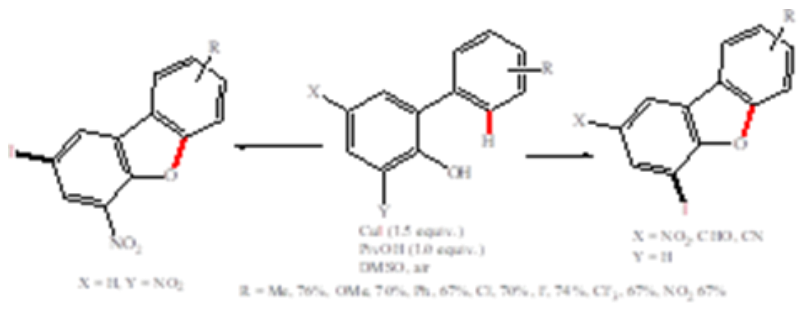

Ning Jiao and coworker's explained Chemo selective oxidative coupling of methyl ketones by using TEMP and copper cocatalyzed with alcohol, the oxidation of methyl ketones by using copper catalyst in the presence of oxygen to have expected products [61,62]. (Scheme 4) 


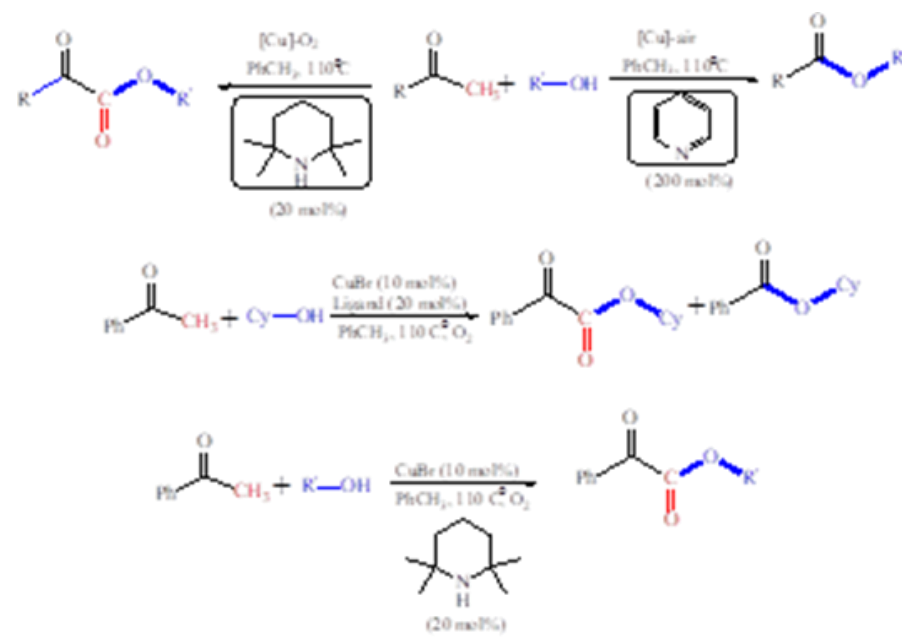

(Scheme 4)

The intermolecular oxidation of $\mathrm{C}-\mathrm{H}$ coupling of indole derivatives and heteroarenes for medium-ring was reported by Greaney and coworkers [63-66]. Intermolecular oxidation by using palladium (II) metal catalysis was explained by Aijun Lin and coworkers [67]. (Scheme 5)
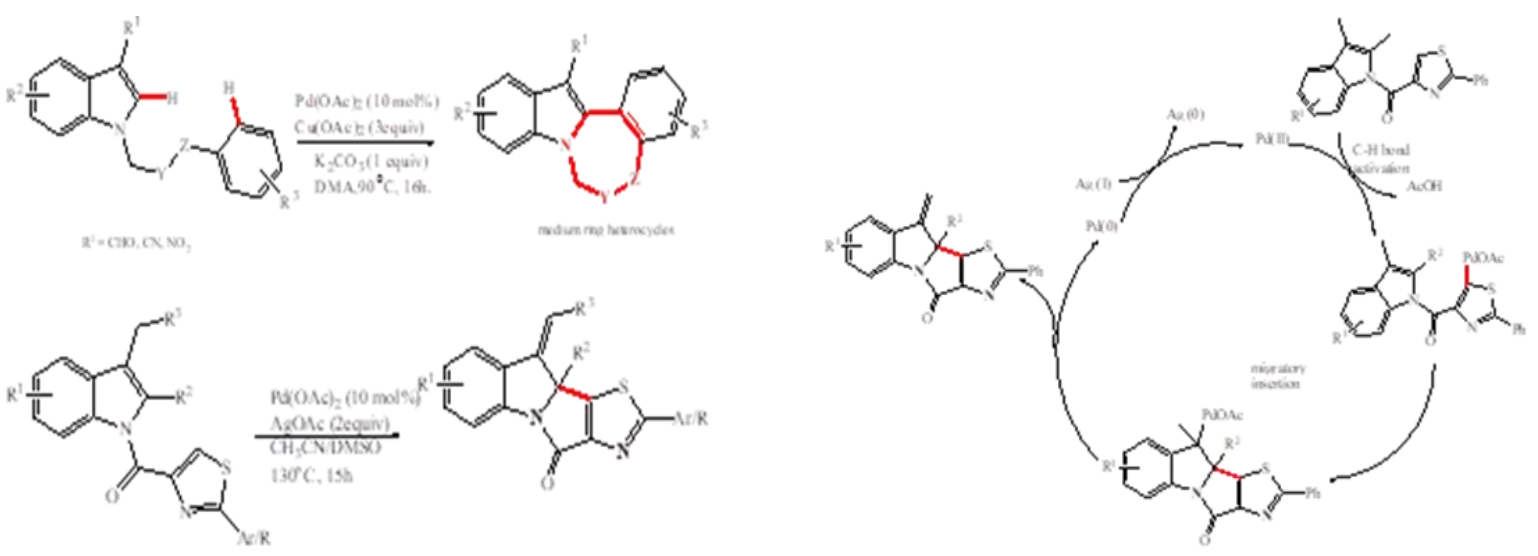

(Scheme 5)

\subsection{Heterocyclic C-N bonds formation}

Heterocyclic compounds are highly important because of their abundance in numerous natural products such as vitamins [68] and alkaloids [69] as well as pharmaceuticals of biological activity [70] and electroactive materials [71]. From this point the synthesis of $\mathrm{C}-\mathrm{N}$ or $\mathrm{C}-\mathrm{O}$ by the activation of $\mathrm{C}-\mathrm{H}$ bond is very important. Xin $\mathrm{W}$. and co-worker [72] synthesis new heterocyclic by the amination of five member heterocyclic ring with Metal or organocatalysis. To optimize the reaction of 2-Acetylfuran $\mathbf{1 0}(0.5 \mathrm{mmol})$ and saccharin (2.0 equiv) as substrates, under atmospheric conditions in the presence of $\mathrm{CuCl}(10 \mathrm{~mol} \%)$ and select Fluor (2.0 equiv) at $120{ }^{\circ} \mathrm{C}$ for $6 \mathrm{~h}$ with nitro methane $\left(\mathrm{CH}_{3} \mathrm{NO}_{2}\right)$ as the solvent, the desired imidation product 1-(5-aminofuran-2-yl)ethanone 11 was obtained in $55 \%$ yield (Table 1, entry 1). The yield of 11 could be increased to $71 \%$ by employing $\mathrm{Cu}(\mathrm{OAc})_{2}$ as the catalyst (Table 1, entry 4). No reaction was observed in the absence of copper salts (Table 1, entry 5). Other oxidants such as $\mathrm{Ce}\left(\mathrm{SO}_{4}\right)_{2}, \mathrm{~K}_{2} \mathrm{~S}_{2} \mathrm{O}_{8}$ Based, and $\mathrm{PhI}(\mathrm{OAc})_{2}$ did not perform well (Table 1). After detailed screening, tert-butyl-hydroperoxide (TBHP) was found to be the best oxidant and the desired 2-imidation product 35. When the Copper salt catalyst was substituted with organocatalytic $\mathrm{nBuNI}$; satisfactorily, the b-imidation product 36 could be obtained in $89 \%$ yield (Table 1). The use of $\mathrm{nBu}_{4} \mathrm{NBr}, \mathrm{KI}$, and I2 instead of nBuNI decreased the yields of 35 to $42 \%, 69 \%$, and $0 \%$, respectively (Table 1) 

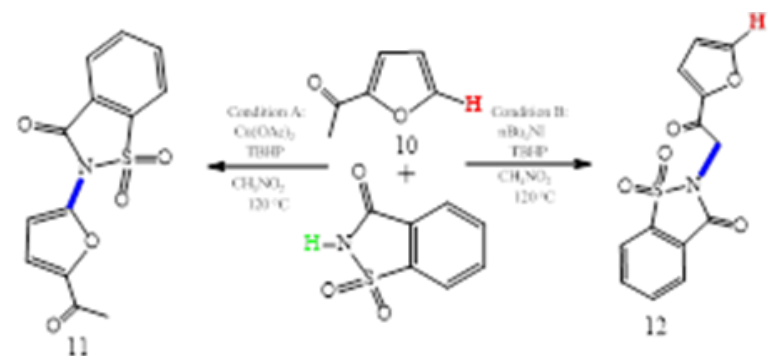

Table 1 Optimization of the reaction conditions

\begin{tabular}{|l|l|l|l|l|}
\hline Entry & Catalyst & Oxidant & Yield 11 & Yield 12 \\
\hline 1 & $\mathrm{CuCl}$ & Selectfluor & 55 & 0 \\
\hline 2 & $\mathrm{CuBr}$ & Selectfluor & 47 & 0 \\
\hline 3 & $\mathrm{Cu}(\mathrm{Otf})_{2}$ & Selectfluor & 61 & 0 \\
\hline 4 & $\mathrm{Cu}(\mathrm{Oac})_{2}$ & Selectfluor & 71 & 0 \\
\hline 5 & $\mathrm{No}$ & Selectfluor & 0 & 0 \\
\hline 6 & $\mathrm{Cu}(\mathrm{Oac})_{2}$ & $\mathrm{Ce}\left(\mathrm{SO}_{4}\right)_{2}$ & 0 & 0 \\
\hline 7 & $\mathrm{Cu}(\mathrm{Oac})_{2}$ & $\mathrm{~K}_{2} \mathrm{~S}_{2} \mathrm{O}_{8}$ & 0 & 0 \\
\hline 8 & $\mathrm{Cu}(\mathrm{Oac})_{2}$ & $\mathrm{PhI}_{2}(\mathrm{Oac})_{2}$ & 23 & 0 \\
\hline 9 & $\mathrm{Cu}(\mathrm{Oac})_{2}$ & TBHP & 91 & 0 \\
\hline 10 & $\mathrm{nBu} 4 \mathrm{NI}$ & TBHP & 0 & 89 \\
\hline 11 & $\mathrm{nBu} 4 \mathrm{NBr}$ & TBHP & 0 & 42 \\
\hline 12 & $\mathrm{KI}_{1}$ & TBHP & 0 & 69 \\
\hline 13 & $\mathrm{I}_{2}$ & TBHP & 0 & 0 \\
\hline 14 & $\mathrm{nBu} 4 \mathrm{NI}$ & DTBP & 0 & 83 \\
\hline
\end{tabular}

Direct heterocyclic C-H bond amination was carried using aerobic oxidation in presence of metal-catalysis. The copper catalysis in aerobic condition was used in the amination of heterocyclic inactive $\mathrm{sp}^{3} \mathrm{C}-\mathrm{H}$ in presence of $\mathrm{K}_{2} \mathrm{CO}_{3}$. The aerobic cross-coupling of heterocyclic (13) with nucleophiles would lead to the 2-amido-substituted heterocyclic (14) through the organocopper intermediate (15) in analogy to the Chan-Lam oxidative coupling of arylboronic acids and nucleophiles [73-83].

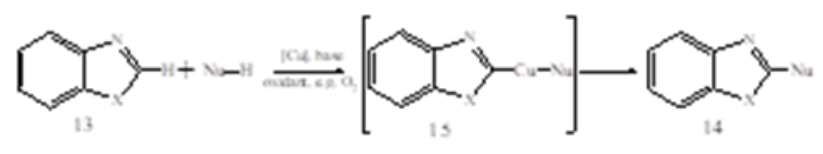

The oxidation reaction of N-methylbenzimidazole (16) to obtain pyrrolidinone (17) was carried out in the presence of catalytic copper salts and less than 1 atom of $\mathrm{O}_{2}$. In the initial screening of $\mathrm{Cu}$ sources, BrØnsted bases, and solvents, optimal results were observed with 0.2 equiv of $\mathrm{Cu}(\mathrm{OAc})_{2}$ and 2 equi of $\mathrm{Na}_{2} \mathrm{CO}_{3}$ with pyridine as additive in toluene [88]. (Scheme 6) 

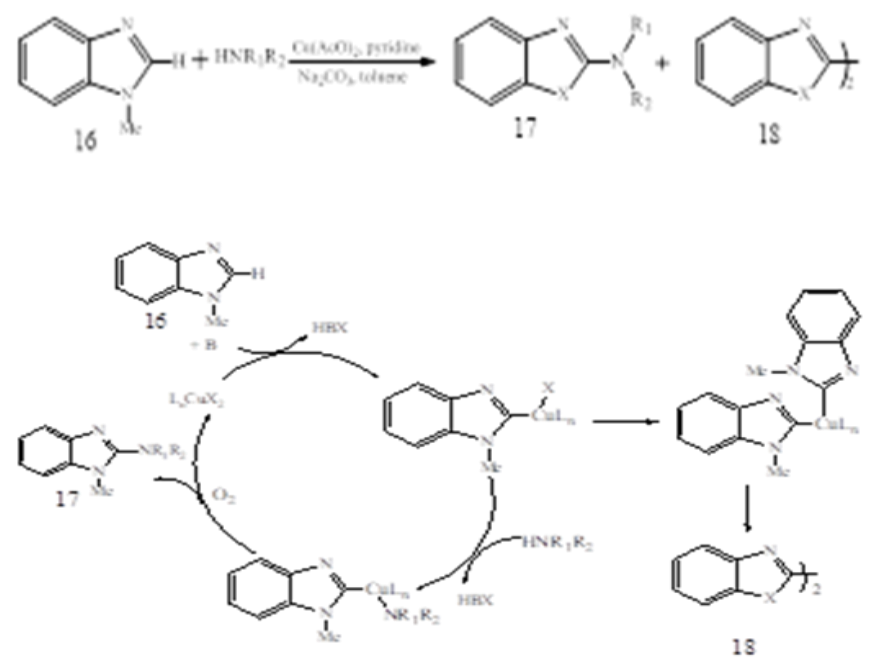

(Scheme 6)

In the other way the intermolecular amination was obtained by using copper salt catalysis. The $\mathrm{Cu}$-catalyzed $\mathrm{sp}^{3} \mathrm{C}-\mathrm{H}$ aminativecyclization of 2-alkyl-N-arylbenzamides has been developed by using di-tert-butyl peroxide, and various substituted substrates were found to be suitable for the reaction. This process provides a powerful approach to synthesize N-aryl-isoindolinones (table 2) [89].
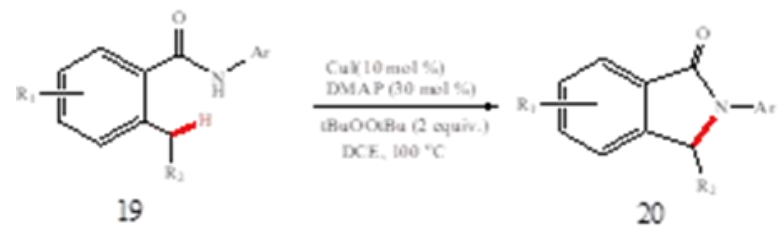

Table 2 reaction conditions with the yield

\begin{tabular}{|l|l|l|l|l|}
\hline Entry & Cu (mol \%) & Ligand (mol \%) & Solvent & Yield (\%) \\
\hline 1 & $\mathrm{CuI}(20)$ & none & benzen & trace \\
\hline 2 & $\mathrm{CuI}(20)$ & Phen (40) & benzen & 15 \\
\hline 3 & $\mathrm{CuI}(20)$ & bipy (40) & benzen & 13 \\
\hline 4 & $\mathrm{CuI}(20)$ & pyridine (40) & benzen & 17 \\
\hline 5 & $\mathrm{CuI}(20)$ & pyridine (40) & toluene & 22 \\
\hline 6 & $\mathrm{CuI}(20)$ & pyridine (40) & DMSO & trace \\
\hline 7 & $\mathrm{CuI}(20)$ & pyridine (40) & DCE & 57 \\
\hline 8 & $\mathrm{Cu}(0 \mathrm{Oac}) 2(20)$ & pyridine (40) & DCE & 26 \\
\hline 9 & $\mathrm{CuBr}(20)$ & pyridine (40) & DCE & 46 \\
\hline 10 & $\mathrm{CuBr}(20)$ & pyridine (40) & DCE & 47 \\
\hline 11 & $\mathrm{CuI} \mathrm{(20)}$ & $4-M e 0-P y(40)$ & DCE & 65 \\
\hline 12 & $\mathrm{CuI} \mathrm{(20)}$ & DMAP (40) & DCE & 86 \\
\hline 13 & $\mathrm{CuI} \mathrm{(10)}$ & DMAP (3) & DCE & 85 \\
\hline
\end{tabular}

The direct $\mathrm{C}-\mathrm{H}$ amination of arenes was carried out by cobalt (III)-catalysis and $\mathrm{O}$-acylcarbamates as a convenient amino source as imino source. The reaction of 2-phenylpyridine $\mathbf{2 4}$ was reacted with aroyloxy carbamate as an amidating 
reagent when $\mathrm{CoCp}^{*}(\mathrm{CO}) \mathrm{I}_{2}(8 \mathrm{~mol} \%)$ employed as a catalyst in the presence of $\mathrm{AgSbF}_{6}(16 \mathrm{~mol} \%)$ was in acetone at 60 ${ }^{\circ} \mathrm{C}$. Direct C-H Amidation of 6-Arylpurine Derivatives was obtained by using N-Boc moiety and the cobalt (III)-catalysis [90-92]. (Scheme 7)
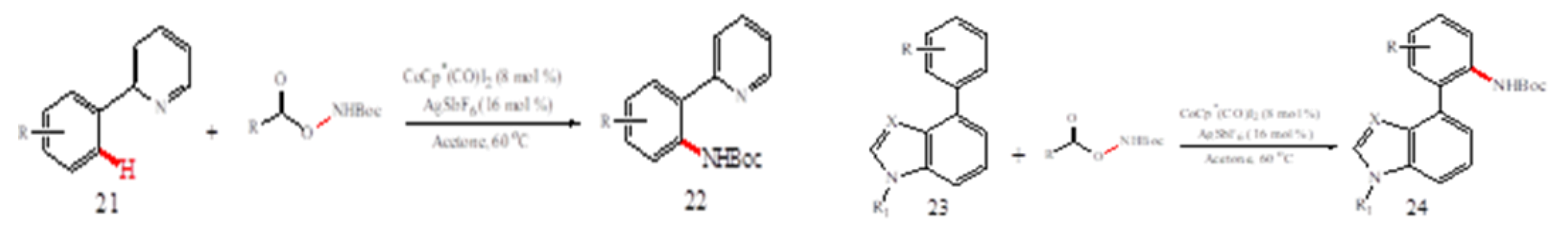

(Scheme 7)

Recently, the Heterocyclic $\mathrm{sp}^{3} \mathrm{C}-\mathrm{H}$ bond functionalization was obtained with the palladium catalyst. The reaction of pyrrolidine derivative $\mathbf{2 5}$ with $p$-substituted toluene to have $\mathrm{C}-\mathrm{C}$ bond 3-arylated pyrrolidine $\mathbf{2 6}$ by using $\mathrm{Pd}(\mathrm{Oac})_{2}(5$ mol \%) [91-92]. (Scheme 8)
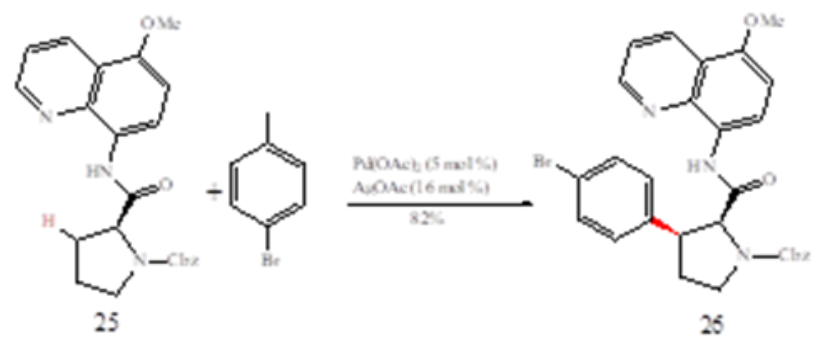

(Scheme 8)

\subsection{C-C bond formation}

The heterocyclic $\mathrm{C}-\mathrm{C}$ bond formation by the $\mathrm{sp}^{3} \mathrm{C}-\mathrm{H}$ activation using metal catalysis was obtained by Liu and coworkers, [93] by the $\mathrm{C}-\mathrm{H}$ bond functionalization of the alkylarylation of alkenes with simple alkanes in the presence of dicumyl peroxide and a copper salt as a catalyst, the unsaturated benzamide $\mathbf{2 7}$ reacts with alkanes, to form the oxindole [94]. The oxy radical abstracts a hydrogen from the alkane and the resulting alkyl radical adds to the unsaturated amide to generate a new radical that reacts intramolecularly with the benzene ring to ultimately form $\mathbf{2 8}$.<smiles>CC(=O)[C@H]([O-])N([14CH3])c1ccccc1I</smiles><smiles>CN1C(=O)C(C)(C)C(C)(CC2CCCCC2)c2ccccc21</smiles>

The oxidation of the imidazopyridine 29 was carried out by using of Langlois reagent and a silver-catalyzed oxidative trifluoromethylation to obtain the trifluoromethyl derivative 30 [95]. tert-butyl hydrogen peroxide (TBHP) was used as the oxidant and the silver catalyst was used as the radical abstract from the trifluoromethyl radical.

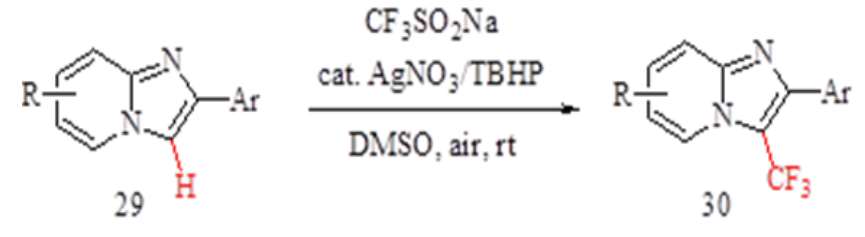

(Scheme 9)

For more reactions of regioselective of heterocyclic C-H bond activation Yamaguchi and co-workers used the palladium and/or copper salts as catalyst, [96] the regioselective functionalization of 4-nitropyrazoles, Palladium- or nickelcatalyzed conditions were curried for the selective arylation at $\mathrm{C}-5$, as illustrated for the conversion of the imidazole 34 to 35 (Scheme 8). Under more activation conditions with palladium or copper catalysis, a second arylation was obtained to generate the triaryl derivative 36 [97]. 
World Journal of Advanced Research and Reviews, 2021, 09(01), 001-030

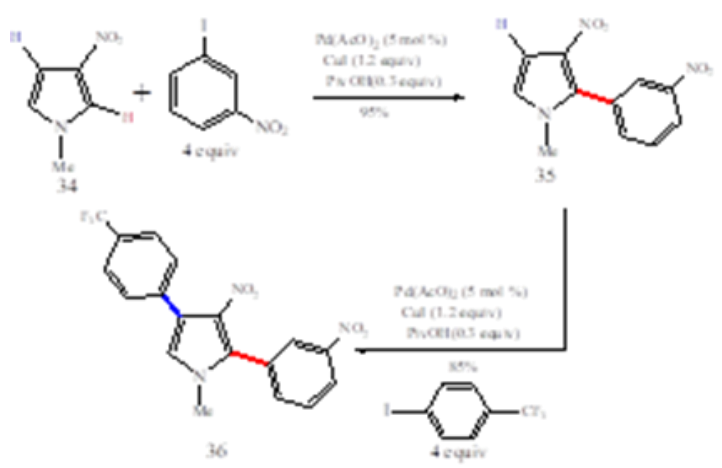

(Scheme 9)

Thus, the heterocyclic $\mathrm{C}-\mathrm{H}$ functionalization was directed to synthesize bioactive and pharmaceutical compounds. The arylation of of benzobisthiazole derivatives 37 converted to the 38 by using palladium and copper salts catalysis. This result is useful in building blocks of bioactive heterocyclic compounds [98].

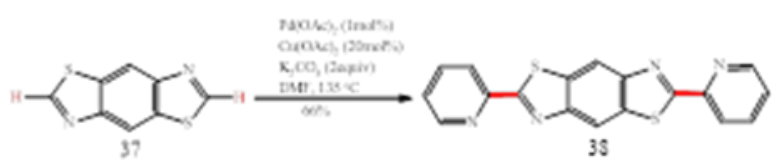

The aromatic C-H activation by using nickel complex [99] was recently reported by Nato Chatani [100]. Nato Chatani used Ni catalyzed transformation of orth $\mathrm{C}-\mathrm{H}$ bonds utilizing, such as oxidative cycloaddition of aromatic amides with alkyne, has been achieved. The Ni-catalyzed transformation of such orth $\mathrm{C}-\mathrm{H}$ bonds utilizing chelation assistance (Scheme 9). The reaction of amide 39 with 4-octyne in the presence of $\mathrm{Ni}(\mathrm{cod}) 2 / \mathrm{PPh} 3$ as the catalyst in toluene at 130 ${ }^{\circ} \mathrm{C}$ for $18 \mathrm{~h}$ gave isoquinolone derivative 40 in $28 \%$ yield as a single product longer reaction time ( 3 days) resulted in an increase in the product yield to $66 \%$.
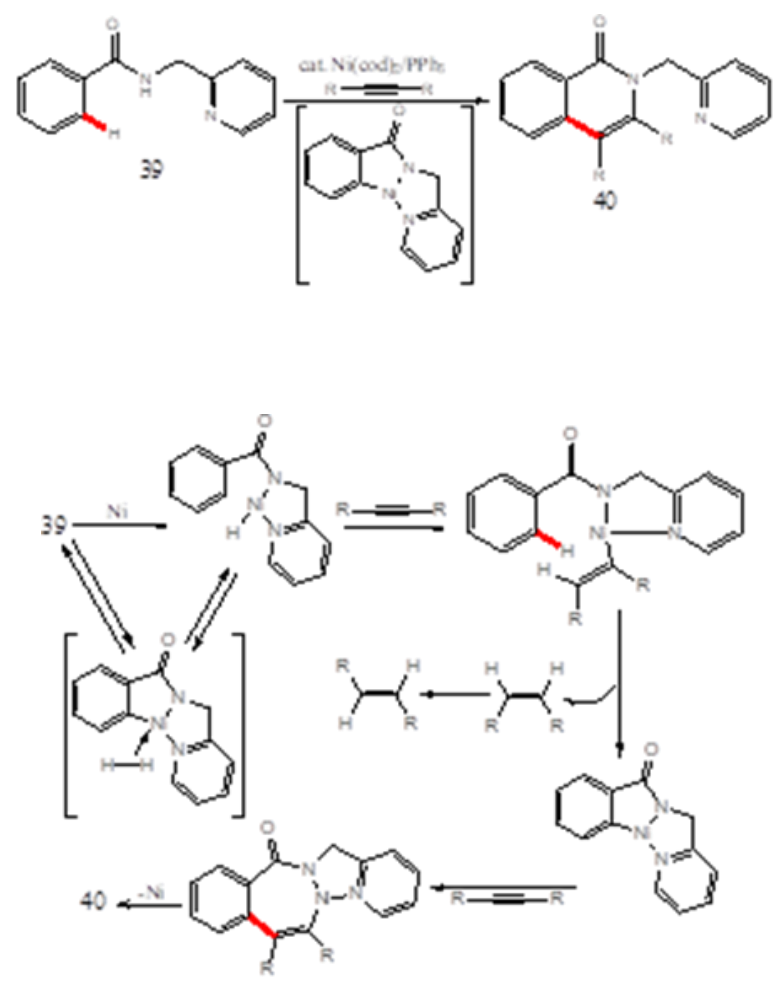

(Scheme 10)

Coupling of quinoline $\mathrm{N}$-oxide with internal alkyne via C-H activation was reported by Nagaraju B; by using Cp*Co(III) catalyzed. Quinoline-N-oxide 41 as a model substrate and diphenylacetylene 42 in the presence of $\mathrm{Cp} * \mathrm{Co}(\mathrm{CO}) \mathrm{I} 2$ (10

9 
mol\%) and NaOAc $(20 \mathrm{~mol} \%)$ in TFE (Trifluoroethanol) at $100^{\circ} \mathrm{C}$ for $24 \mathrm{~h}$ give the expected product 43 [101]. (Scheme 11)
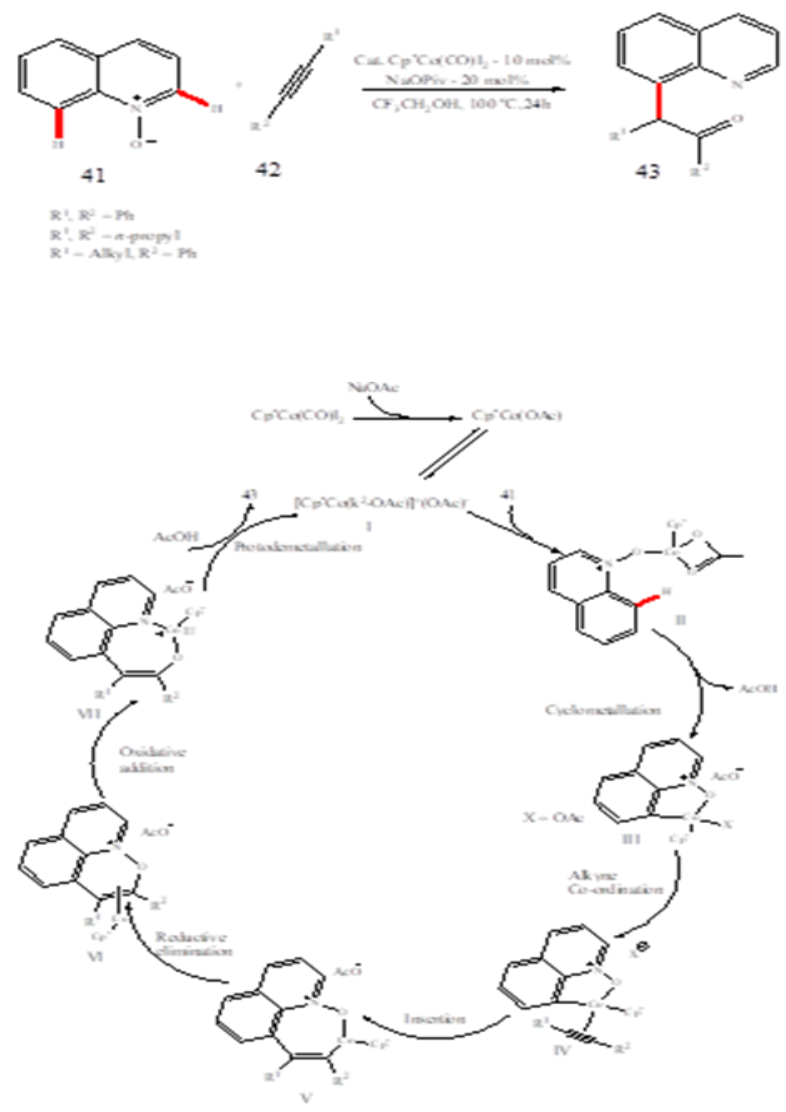

(Scheme 11)

\section{Organocatalysis (metal free) activation of $\mathrm{C}-\mathrm{H}$ bond}

Most of the reported C-H bond functionalization was restricted to the metal-mediated approaches. Recently, Most scientists direct to replace the rare and toxic metal catalysis with organocatalysis such as BrØnsted acids, thiourea derivatives catalysts, tetra-alkylammonium iodide catalysts, etc., (Chen, et al., 2011). Thus, these organocatalysis can be synthesized from cheap materials, and direct to chiral compounds with high efficient and removed from the products easily than the metal catalysis.

\subsection{C-H bond oxidation}

Most reports in the $\mathrm{C}-\mathrm{H}$ bond oxidation were used rare or toxic metal catalysis such as CuI, $\mathrm{Fe}_{2} \mathrm{SO}_{4}, \mathrm{~K}_{2} \mathrm{~S}_{2} \mathrm{O}_{8}, \mathrm{AgOTf}$, $\mathrm{Cu}(\mathrm{OAc})_{2}, \mathrm{~K}_{3} \mathrm{Fe}(\mathrm{CN})_{6}, \mathrm{Fe}(\mathrm{acac})_{3}$, PdIV, Ru, Ir ......etc., [104-112]. The first report in the $\mathrm{C}$ (sp3)-H functionalization with metal free catalyst in the direct transformation of hydrocarbons and N-hydroxyphthalimide (NHPI) to alkyloxyamines by using $\mathrm{n}-\mathrm{Bu} 4 \mathrm{NI}$ catalyst was reported by Yunhe $\mathrm{Lv}$ [113-115]. The reaction of hydrocarbons with NHPI in the presence of n-Bu4NI ( 0.2 equiv.) as catalyst and tert-butyl hydroperoxide (TBHP, 2 equiv.) as oxidant exhibited excellent catalytic activity and gave the desired product in good yield table 3 .

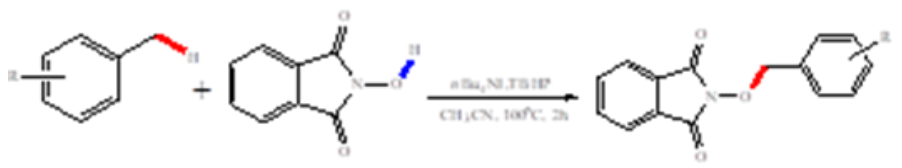


Table 3 reaction conditions with the yield

\begin{tabular}{|c|c|c|c|c|c|}
\hline Entry & Oxidant & Catalyst & Solvent & $\mathbf{T}\left({ }^{\square} \mathbf{C}\right)$ & Yieldc (\%) \\
\hline 1 & TBHP & $\mathrm{n}-\mathrm{Bu}_{4} \mathrm{NI}$ & $\mathrm{CH}_{3} \mathrm{CN} 130$ & 85 & 85 \\
\hline 2 & TBHP & $\mathrm{n}-\mathrm{Bu}_{4} \mathrm{NI}$ & EtOAc & 130 & 73 \\
\hline 3 & TBHP & $\mathrm{n}-\mathrm{Bu}_{4} \mathrm{NI}$ & DCM & 130 & 55 \\
\hline 4 & ТВНP & $\mathrm{KI}$ & $\mathrm{CH}_{3} \mathrm{CN}$ & 130 & 25 \\
\hline 5 & TBHP & $\mathrm{NH}_{4} \mathrm{I}$ & $\mathrm{CH}_{3} \mathrm{CN}$ & 130 & 28 \\
\hline 6 & TBHP & $\mathrm{I}_{2}$ & $\mathrm{CH}_{3} \mathrm{CN}$ & 130 & 0 \\
\hline 7 & TBHP & NIS & $\mathrm{CH}_{3} \mathrm{CN}$ & 13 & Trace \\
\hline 8 & $\mathrm{Na}_{2} \mathrm{~S}_{2} \mathrm{O}_{8}$ & $\mathrm{n}-\mathrm{Bu}_{4} \mathrm{NI}$ & $\mathrm{CH}_{3} \mathrm{CN}$ & 130 & 0 \\
\hline 9 & TBHP & $\mathrm{n}-\mathrm{Bu}_{4} \mathrm{NI}$ & $\mathrm{CH}_{3} \mathrm{CN}$ & 130 & Trace \\
\hline 10 & $\mathrm{H}_{2} \mathrm{O}_{2}$ & $\mathrm{n}-\mathrm{Bu}_{4} \mathrm{NI}$ & $\mathrm{CH}_{3} \mathrm{CN}$ & 130 & 0 \\
\hline 11 & - & $\mathrm{n}-\mathrm{Bu}_{4} \mathrm{NI}$ & $\mathrm{CH}_{3} \mathrm{CN}$ & 130 & Trace \\
\hline 12 & TBHP & - & $\mathrm{CH}_{3} \mathrm{CN}$ & 130 & Trace \\
\hline 13 & TBHP & $\mathrm{n}-\mathrm{Bu} 4 \mathrm{NI}$ & $\mathrm{CH}_{3} \mathrm{CN}$ & 100 & 92 \\
\hline 14 & TBHP & $\mathrm{n}-\mathrm{Bu}_{4} \mathrm{NI}$ & $\mathrm{CH}_{3} \mathrm{CN}$ & 90 & 81 \\
\hline 15 & ТВНP & $\mathrm{n}-\mathrm{Bu}_{4} \mathrm{NI}$ & CH3CN & 70 & 52 \\
\hline
\end{tabular}

The formation of $\mathrm{C}-\mathrm{O}, \mathrm{C}-\mathrm{N}$ and $\mathrm{C}=\mathrm{N}$ via the $\mathrm{C}(\mathrm{sp} 3)-\mathrm{H}$ activation by means of organocatalytic (metal free) reagents was reported by Chengjian Zhu and coauthors [116-119]., by the reaction of active methylene compounds and benzyl amine derivatives in the presence of $\mathrm{n}-\mathrm{Bu} 4 \mathrm{NI}$ as an organocatalyst and TBHP as an oxidant could initiate the reaction at room temperature. The reaction of ethyl acetoacetate 43 with benzylamine 44 in the presence of n-Bu4NI catalyst ( $20 \mathrm{~mol} \%)$, and an oxidant (4.0 equiv.) to have the product 45 with good yield as explained in table 4

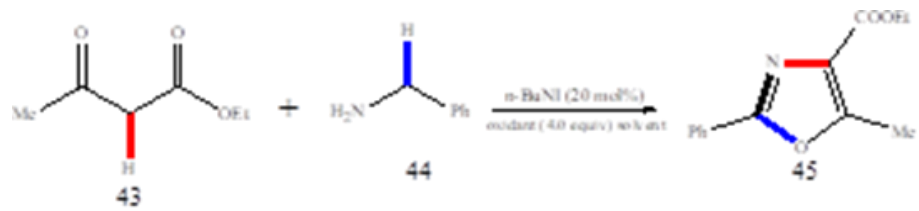

Table 4 reaction conditions with the yield

\begin{tabular}{|c|c|c|c|c|c|}
\hline Entry & Catalyst & Solvent & Oxidant & Time $/ \mathbf{h}$ & Yieldc(\%) \\
\hline 1 & $\mathrm{n}-\mathrm{Bu}_{4} \mathrm{NI}$ & EtOAc & TBHP & 10 & 67 \\
\hline 2 & $\mathrm{n}-\mathrm{Bu}_{4} \mathrm{NCl}$ & EtOAc & TBHP & 24 & 0 \\
\hline 3 & $\mathrm{n}-\mathrm{Bu}_{4} \mathrm{NBr}$ & EtOAc & TBHP & 24 & 0 \\
\hline 4 & $\mathrm{NaI}$ & EtOAc & TBHP & 10 & 45 \\
\hline 5 & $\mathrm{I}_{2}$ & EtOAc & TBHP & 10 & 36 \\
\hline 6 & - & EtOAc & TBHP & 24 & 0 \\
\hline 7 & n-Bu4NI & EtOAc & T-HYDRO & 8 & 70 \\
\hline 8 & n-Bu4 $\mathrm{NI}$ & EtOAc & T-HYDRO & 8 & 32 \\
\hline 9 & n-Bu4 $\mathrm{NI}^{-}$ & EtOAc & T-HYDRO & 6 & $\mathrm{Nd}$ \\
\hline 10 & n-BuN & EtOAc & T-HYDRO & 6 & 61 \\
\hline 11 & n-Bu4nI & EtOAc & T-HYDRO & 8 & 38 \\
\hline 12 & n-Bu4NI & DMF & T-HYDRO & 8 & 10 \\
\hline 13 & $\mathrm{n}-\mathrm{Bu}_{4} \mathrm{NI}$ & $\mathrm{MeCN}$ & T-HYDRO & 8 & 27 \\
\hline
\end{tabular}


The mechanism of the cascade reaction [120] was explained by Ishihara and co-workers, [121] suggested that the active iodine species ammonium hypoiodite $([\mathrm{n}-\mathrm{Bu} 4 \mathrm{~N}]+[\mathrm{IO}]-)$ or iodite $(\mathrm{n}-[\mathrm{Bu} 4 \mathrm{~N}]+[\mathrm{IO} 2]-)$ plays an important role in the cascade sp3 $\mathrm{C}-\mathrm{H}$ activation reaction as in the (scheme 12)

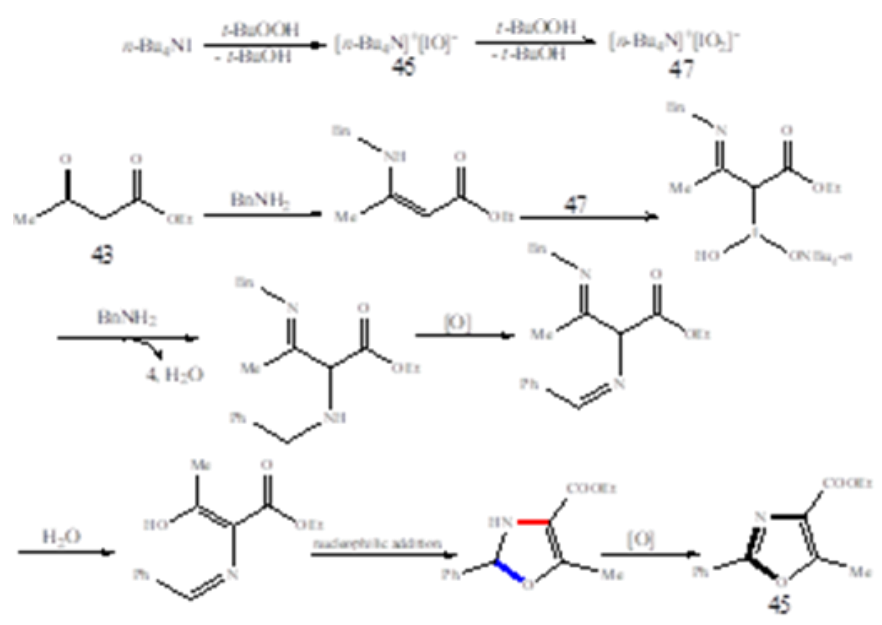

(Scheme 12)

The aerobic C-H oxidation of $\mathrm{C}(\mathrm{sp} 3)-\mathrm{H}$ activation by organocatalytic (metal free) recyclable catalyst TEMPO. TEMPO one of the most choice in industry [122] and has been widely used for the oxidation of alcohols to carbonyls, [123,124], and it use in the oxidative functionalization of other functionalities represents an important challenge and the examples are very limited [125-131]. Recently, Wei Wang and coworkers was reported the oxidation of benzylic C( $\left.\mathrm{sp}^{3}\right)-\mathrm{H}$ by using TEMPO catalyst. The oxidation of benzylic C-H by means of recyclable TEMPO derived sulfonate organocatalysts in presence of $\mathrm{NaNO}_{2}$ and $\mathrm{HCl}$ aqueous solution as the co-catalyst [132-138] and $\mathrm{O}_{2}$ as the oxidant for large-scale [139142]. The aerobic oxidation of isochroman derivatives 46 was treated with $2 \mathrm{~mol} \%$ TEMPO catalyst I, 4 mol \% NaNO2 (solid), and $10 \mathrm{~mol} \%$ concn $\mathrm{HCl}(12.0 \mathrm{M})$ aq solution with an 02 balloon in $3 \mathrm{~mL}$ of $\mathrm{CH} 3 \mathrm{CN}$ at rt to affored ketone 17 (Scheme 13)

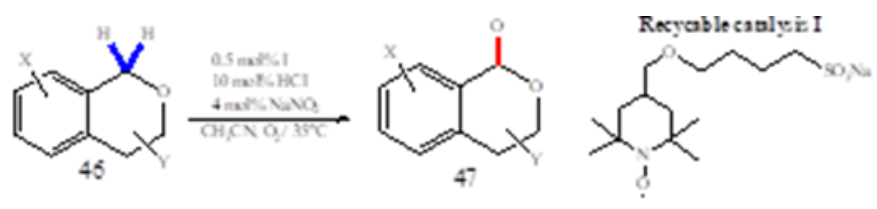

(Scheme 13)

Table 5 reaction conditions with the yield

\begin{tabular}{|l|l|l|l|l|l|}
\hline Entry & Catalyst & I (mol \%) & Oxidant & Time/h & Yieldc(\%) \\
\hline 1 & $\mathrm{CH}_{3} \mathrm{CN}$ & 2 & TBHP & 12 & 59 \\
\hline 2 & $\mathrm{CH}_{3} \mathrm{CN}$ & 2 & TBHP & 8 & 83 \\
\hline 3 & $\mathrm{CH}_{3} \mathrm{CN}$ & 1 & TBHP & 8 & 77 \\
\hline 4 & $\mathrm{CH}_{3} \mathrm{CN}$ & 0.5 & TBHP & 8 & 80 \\
\hline 5 & $\mathrm{CH}_{3} \mathrm{CN}$ & 0.3 & TBHP & 12 & 67 \\
\hline 6 & $\mathrm{ClCH}_{2} \mathrm{CH}_{2} \mathrm{Cl}$ & 0.5 & TBHP & 8 & 57 \\
\hline 7 & THF & 0.5 & T-HYDRO & 8 & 34 \\
\hline 8 & $\mathrm{DMF}$ & 0.5 & T-HYDRO & 8 & 51 \\
\hline 9 & $\mathrm{H}_{2} \mathrm{O}$ & 0.5 & T-HYDRO & 8 & 21 \\
\hline 10 & $\mathrm{CH}_{3} \mathrm{CN}$ & 0.5 & T-HYDRO & 8 & 14 \\
\hline
\end{tabular}


The aerobic oxidation of xanthones 48 into ketones 49 without touch the substituted $\mathrm{S}, \mathrm{N}$, and/or $\mathrm{O}$ atoms with good yield in the presence of TEMPO recyclable catalysis was also studied (Scheme 14)

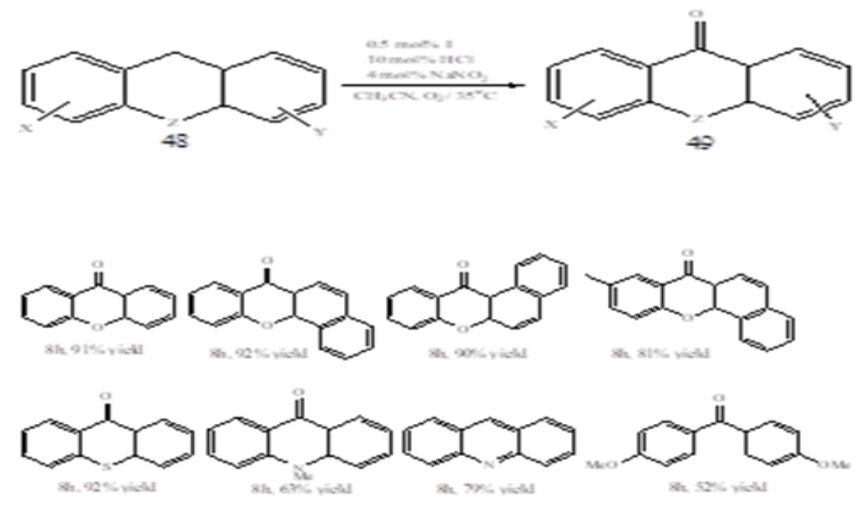

(Scheme 14)

Kazuaki I. and couther's was reported chiral hypervalent iodine compounds for enantioselective oxidative coupling to proven a particular challenge in asymmetric catalysis [143,144]. The oxidation of compound 50 was carried out with aryl- $\lambda 3$-iodanes as pre-catalyst in the presence of co-oxidant hydrogen peroxide or TBHP to have 51 (Scheme 15)

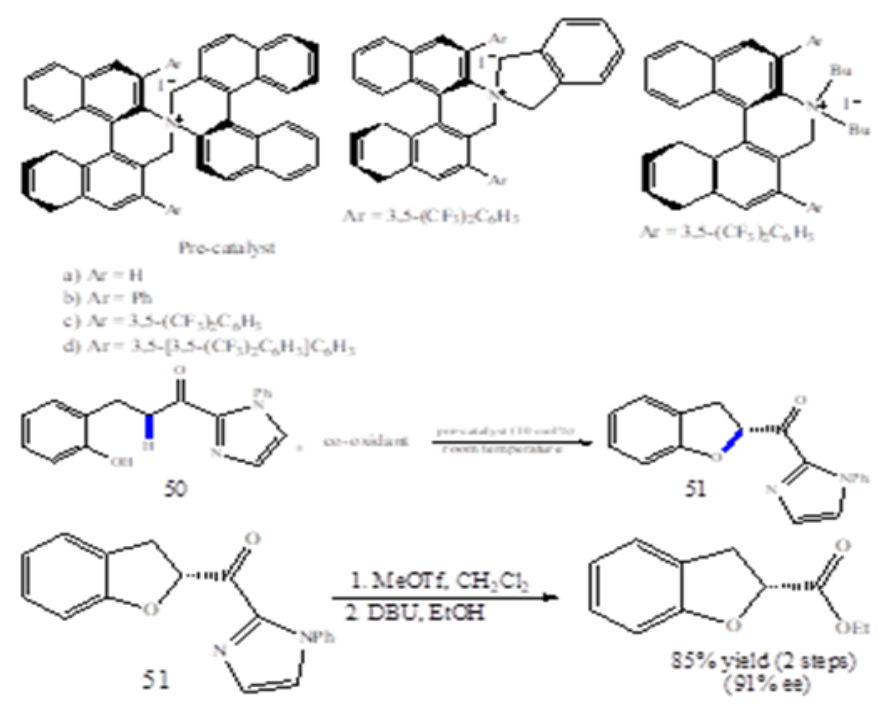

(Scheme 15)

\subsection{C-C bond formation}

One of the most important C-H bond functionalization is C-C bond formation. Recently, there are many reports studied the development of methods for the functionalization of $\mathrm{C}-\mathrm{H}$ bonds using metals catalysis or other oxidative reagents to afford C-C bonds [145-154]. The cynation of tetrahydroquinoline derivatives 52 and 1,3-diarylpropenes 54 using TMSCN in presence of 2,3-dichloro-5,6-dicyano-1,4-benzoquinone (DDQ) as a catalyst under air condition to have the cyano compounds 53, 55 was reported by Min Wang and coworkers, [155-157] the reaction of $0.5 \mathrm{mmol}$ of tetrahydroqinoline derivatives and $1.5 \mathrm{mmol}$ of TMSCN in presence of $0.6 \mathrm{mmol}$ of DDQ as a catalyst under air to have the cyano compound 53. (Scheme 16) 


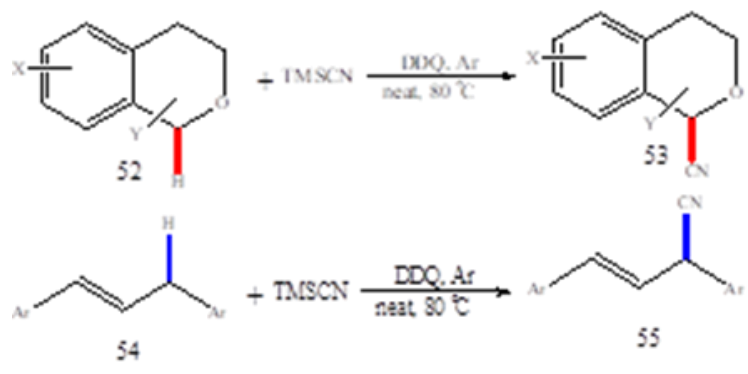

\begin{tabular}{|l|l|l|}
\hline Entry & $\mathbf{5 4}, \mathrm{Ar}$ & Yield[\%] \\
\hline 1 & $54 \mathrm{a}, \mathrm{Ph}$ & $55 \mathrm{a}, 74$ \\
\hline 2 & $54 \mathrm{~b}, 4-\mathrm{F}-\mathrm{C}_{6} \mathrm{H}_{4}$ & $55 \mathrm{~b}, 57$ \\
\hline 3 & $54 \mathrm{c}, 4-\mathrm{Cl}_{-} \mathrm{C}_{6} \mathrm{H}_{4}$ & $55 \mathrm{c}, 62$ \\
\hline 4 & $54 \mathrm{~d}, 4-\mathrm{Br}^{-} \mathrm{C}_{6} \mathrm{H}_{4}$ & $55 \mathrm{~d}, 58$ \\
\hline 5 & $54 \mathrm{e}, 4-\mathrm{Me}-\mathrm{C}_{6} \mathrm{H}_{4}$ & $55 \mathrm{e}, 50$ \\
\hline 6 & $54 \mathrm{f}, 4-\mathrm{tBu}-\mathrm{C}_{6} \mathrm{H}_{4}$ & $55 \mathrm{f}, 68$ \\
\hline
\end{tabular}

(Scheme 16)

Cross-dehydrogenative coupling (CDC) reactions are one of the most commonly used as atom-economic methods [158165]. Rare, expensive metals and stoichiometric amounts of peroxides and harsh reaction conditions have used on most of $\mathrm{CDC}$ reactions. Recently, the catalytic methods for $\mathrm{C}(\mathrm{sp} 3)-\mathrm{H}$ bond arylation at the $\mathrm{C}(1)$ position of isochroman are still limited [165]. The activation of $\mathrm{C}(\mathrm{sp} 3)-\mathrm{H}$ of isochromine by the combination of N-hydroxy-2-azaadamantane (AZADOL) and PIFA to introduce the aryl and various functional groups into the position 1 was reported by Wataru Muramatsu and Kimihiro Nakano.91 Isochomine derivatives was initiated by AZADOL (5.0 mol\%) and PIFA (1.1 equv.) in 1,2-dichloroethane (DCE), followed by nucleophilic addition using R $\backslash \mathrm{MgI} / \mathrm{Et} 20$ (2.0 equiv.) [166-169]. (Scheme 17)

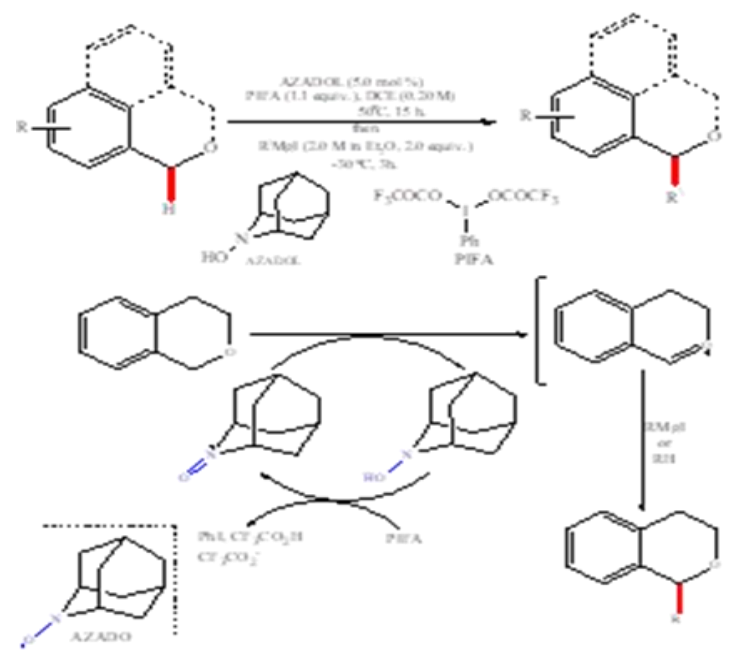

(Scheme 17)

Asymmetric catalyst plays an important role in the $\mathrm{C}-\mathrm{H}$ bond functionalization and numerous catalytic asymmetric reactions have been developed with various activation modes [170-175]. Using of chiral bifunctional thioureas bearing multiple hydrogen-bond donors successfully used as chiral organocatalysts for the asymmetric Michael addition and Mannich reactions [176]. However, Henry reaction is one of the most important carbon-carbon bond-forming reactions that provide straightforward access to $\beta$-nitroalcohols compounds [177-179]. The reaction of pyrrole derivatives 56 and nitro derivatives 57 in the presence of various chiral bifunctional organocatalysts 58 in dichloromethane to synthesized chiral pyrrole derivatives 59 [180-182]. (Scheme 18) 


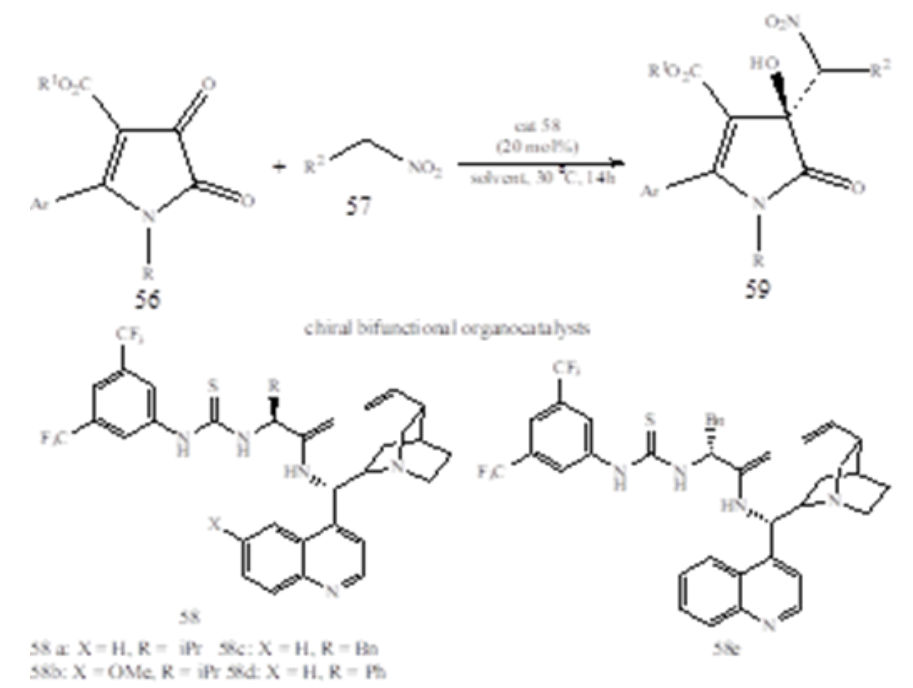

\begin{tabular}{|c|c|c|c|c|c|}
\hline Entry & $\mathbf{R} / \mathbf{R}^{1} / \mathbf{A r}$ & $\mathbf{R}^{2}$ & Time & Yield \% & ee\% \\
\hline 1 & $\mathrm{iPr} / \mathrm{Me} / \mathrm{Ph}$ & $\mathrm{H}$ & 14 & 55 & 65 \\
\hline 2 & $\mathrm{iPr} / \mathrm{n}-\mathrm{Bu} / \mathrm{Ph}$ & $\mathrm{H}$ & 70 & 52 & 70 \\
\hline 3 & $\mathrm{iPr} / \mathrm{Et} / 2-\mathrm{ClC}_{6} \mathrm{H}_{4}$ & $\mathrm{H}$ & 62 & 53 & $73^{\mathrm{d}}$ \\
\hline 4 & $\mathrm{iPr} / \mathrm{Et} / 3-\mathrm{MeOC}_{6} \mathrm{H}_{4}$ & $\mathrm{H}$ & 62 & 73 & 71 \\
\hline 5 & $\mathrm{iPr} / \mathrm{Et} / 3-\mathrm{ClC}_{6} \mathrm{H}_{4}$ & $\mathrm{H}$ & 120 & 47 & 71 \\
\hline 6 & $\mathrm{iPr} / \mathrm{Et} / 3-\mathrm{BrC}_{6} \mathrm{H}_{4}$ & $\mathrm{H}$ & 120 & 44 & 70 \\
\hline 7 & $\mathrm{iPr} / \mathrm{Et} / 4-\mathrm{MeOC}_{6} \mathrm{H}_{4}$ & $\mathrm{H}$ & 62 & 61 & 72 \\
\hline 8 & $\mathrm{iPr} / \mathrm{Et} / 4-\mathrm{MeC}_{6} \mathrm{H}_{4}$ & $\mathrm{H}$ & 48 & 64 & 69 \\
\hline 9 & $\mathrm{iPr} / \mathrm{Et} / 4-\mathrm{FC}_{6} \mathrm{H}_{4}$ & $\mathrm{H}$ & 62 & 73 & 70 \\
\hline 10 & iPr/Et/2-thienyl & $\mathrm{H}$ & 120 & 51 & 71 \\
\hline 11 & iPr/Et/1-naphthyl & $\mathrm{H}$ & 120 & 75 & $51^{e}$ \\
\hline 12 & $\mathrm{H} / \mathrm{Me} / \mathrm{Ph}$ & $\mathrm{H}$ & 120 & 41 & 48 \\
\hline 13 & $\mathrm{Ph} / \mathrm{Et} / \mathrm{Ph}$ & $\mathrm{H}$ & 120 & 42 & 29 \\
\hline 14 & $\mathrm{iPr} / \mathrm{Et} / \mathrm{Ph}$ & $\mathrm{Me}$ & 24 & 23 & $22^{\mathrm{f}}$ \\
\hline 15 & $\mathrm{iPr} / \mathrm{Me} / 4-\mathrm{MeOC}_{6} \mathrm{H}_{4}$ & $\mathrm{H}$ & 84 & 51 & 69 \\
\hline 16 & $\mathrm{iPr} / \mathrm{Me} / 3-\mathrm{MeOC}_{6} \mathrm{H}_{4}$ & $\mathrm{H}$ & 120 & 71 & 58 \\
\hline
\end{tabular}

Direct $\beta$-indolylation of enals, the investigation of an efficient metal-free organocatalysed $\mathrm{C}-\mathrm{H} \alpha$-arylation reaction of enals remains highly challenging [183-187]. There is very few reports about the metal free approach for the direct $\mathrm{C}(\mathrm{sp} 2)-\mathrm{C}(\mathrm{sp} 2)$ cross-coupling $\alpha$-indolylation of enals from unfunctionalized indoles and enals. Xinhong Yu and coworkers was reported the one-pot operation, the perquisite 3-bromoindoles could be in situ produced from an electrophilic bromination reaction of indoles with pyridine hydrobromide perbromide, thereby creating an ambiphilic nucleophilic/electrophilic center for the subsequent Michael addition initial cascade process. The reaction of indole derivatives 60, with trans-cinnamaldehyde derivatives 61 in the presence of pyridine hydrobromide perbromide, racemic diphenylprolinol trimethylsilyl ether (A, 20 mol\%) and base NaOAc were carried out in toluene (Tol) [188,189] to obtain the desired product 62 . (Scheme 19, table 6) 


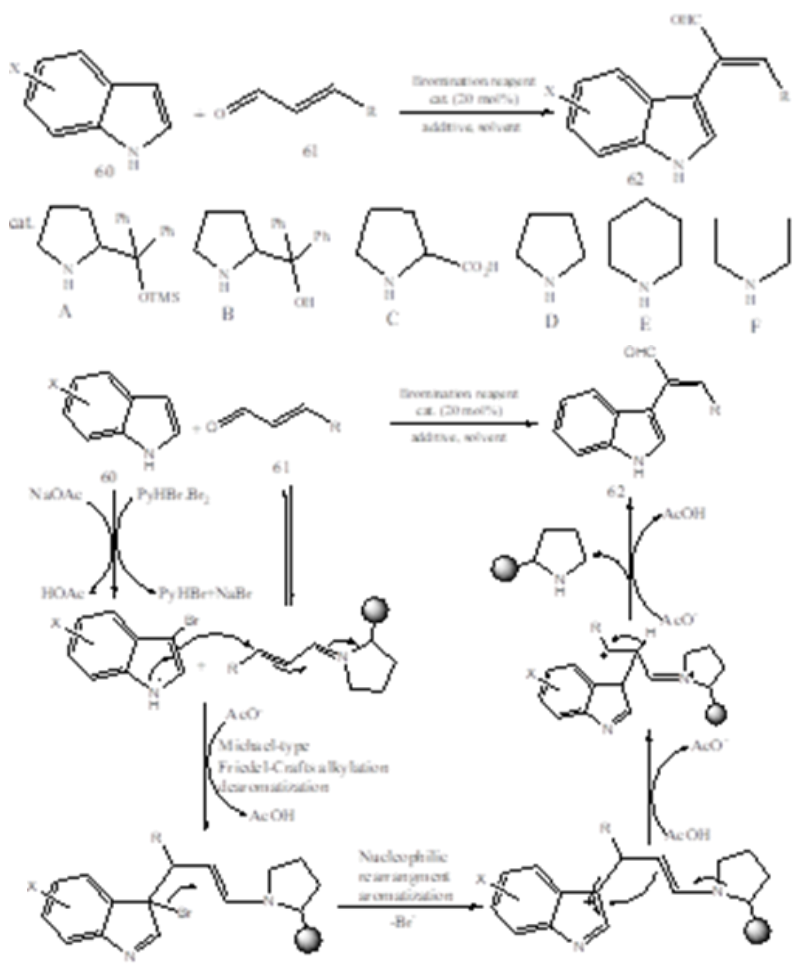

(Scheme 18)

Table 6 reaction conditions with the yield.

\begin{tabular}{|c|c|c|c|c|c|}
\hline Entry & Cat. & Bromination reagent & Solvent & Additive & Yield (\%) \\
\hline 1 & A & & Toluene & $\mathrm{NaOAc}$ & 32 \\
\hline 2 & A & & $\mathrm{MeCN}$ & $\mathrm{NaOAc}$ & 35 \\
\hline 3 & A & & $\mathrm{CHCl}_{3}$ & $\mathrm{NaOAc}$ & 30 \\
\hline 4 & A & & Tol: $\mathrm{CHCl}_{3}(1: 1)$ & $\mathrm{NaOAc}$ & 62 \\
\hline 5 & A & & Tol: $\mathrm{CHCl}_{3}(1: 1)$ & TEA & 42 \\
\hline 6 & A & NBS & Tol: $\mathrm{CHCl}_{3}(1: 1)$ & $\mathrm{NaOAc}$ & 50 \\
\hline 7 & B & & Tol: $\mathrm{CHCl}_{3}(1: 1)$ & $\mathrm{NaOAc}$ & - \\
\hline 8 & $\mathrm{C}$ & & Tol: $\mathrm{CHCl}_{3}(1: 1)$ & $\mathrm{NaOAc}$ & - \\
\hline 9 & $\mathrm{D}$ & & Tol: $\mathrm{CHCl}_{3}(1: 1)$ & $\mathrm{NaOAc}$ & - \\
\hline 10 & $\mathrm{E}$ & & Tol: $\mathrm{CHCl}_{3}(1: 1)$ & $\mathrm{NaOAc}$ & 10 \\
\hline 11 & $\mathrm{~F}$ & & Tol: $\mathrm{CHCl}_{3}(1: 1)$ & $\mathrm{NaOAc}$ & - \\
\hline
\end{tabular}


The organocatalysis is possibile to use in the SN1-type reactions [190-192]. Pier Giorgio Cozzi and coworkers used stabilized carbocations generated by benzylic alcohols in situ for the enantioselective a-alkylation of aldehydes [193195]. However, the activation of $\mathrm{C}-\mathrm{H}$ bonds of alkanes could be coupled with a direct stereo selective organocatalytic reaction [196-198]. This methodology has enormous potential, as all concepts developed in organocatalytic reactions can be used in the direct functionalization of $\mathrm{C}-\mathrm{H}$ bonds, with all the advantages of simple reaction conditions, and absence of metal catalysts.

DDQ is a well-known oxidizing reagent for organic synthesis, [199] and the coupling reaction between nucleophiles and benzylic substrates mediated [196-203]. The reaction was promoted by the MacMillan-type of catalyst [196,-204], while chiral diphenylprolinol TBS ether catalyst [205], did not prove effective in this transformation. $\alpha$-Alkylation of compounds xanthene 63,1,3,5-cycloheptatriene 64,65 , and 66 was reacted with aldehydes by using organocatalysis 67, 68 [206-208]. (Scheme 19)<smiles>c1ccc2c(c1)Cc1ccccc1O2</smiles>

63<smiles>c1ccccc1</smiles>

6<smiles>CC1=CCc2ccccc2N1</smiles>

6<smiles>CCc1c(C)[nH]c2ccccc12</smiles>
$\mathrm{N}=\mathrm{F}$ $\mathrm{Ar}=\mathrm{aNO} \mathrm{NO}_{2}$ Ar $=$ P-MeOP

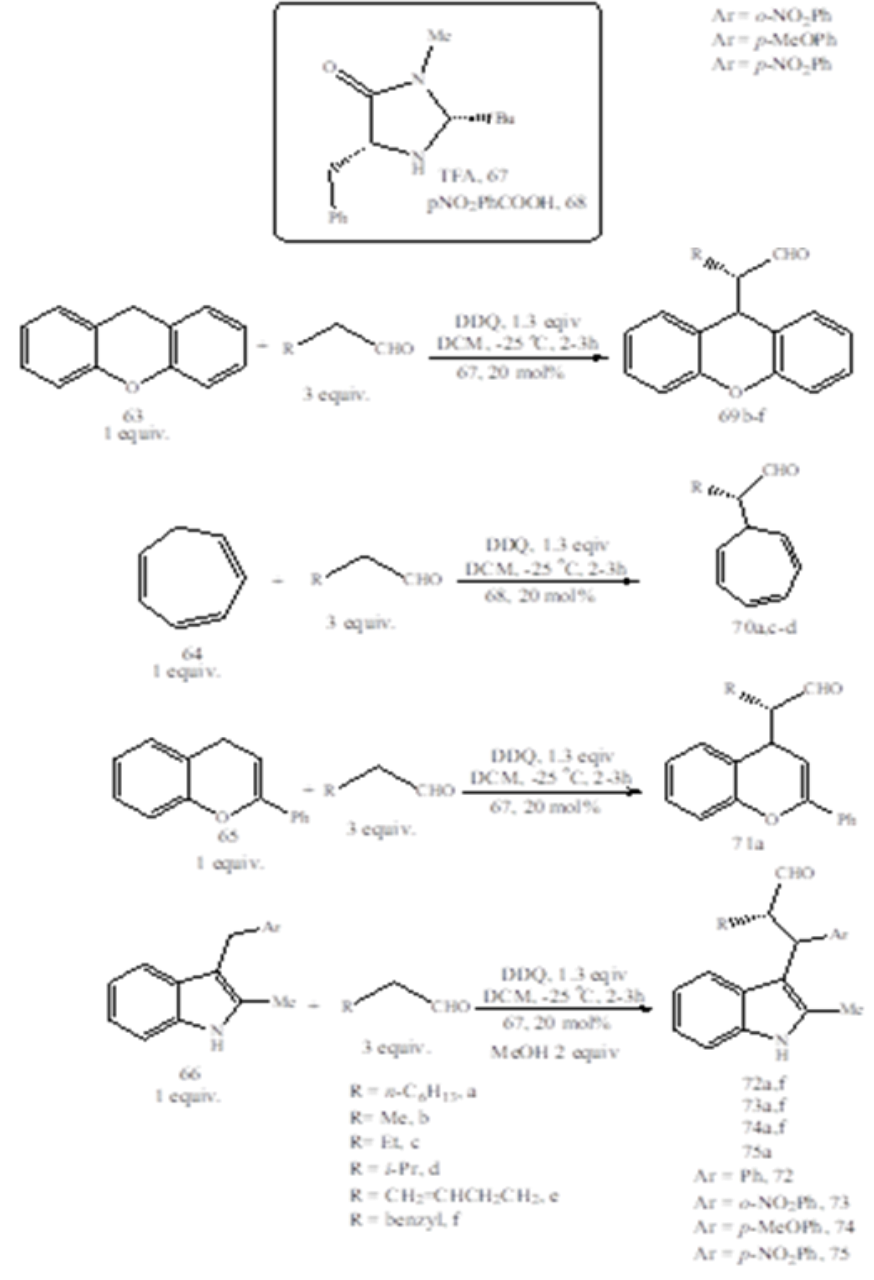
$\mathrm{Ar}=\mathrm{PNO}, \mathrm{Ni}$

(Scheme 19)

Addition reaction to carbonyl, imine, and $\alpha, \beta$-unsaturated carbonyl compounds, such as Friedel-Crafts alkylations, using catalytic asymmetric sp2 $\mathrm{C}-\mathrm{H}$ bond, is one of a powerful challenging organic transformation $[207,208]$. When $(76)$ reacted with an acyl imine 77 was attempted at room temperature in chloroform-d1 under the influence of $2 \mathrm{~mol} \%$ of achiral phosphoric acid (78). Starting imine (77) to the direct alkylation product (79) was observed within $1 \mathrm{~h}$, and the product was isolated in 70\% yield [209-215]. (Scheme 20) 


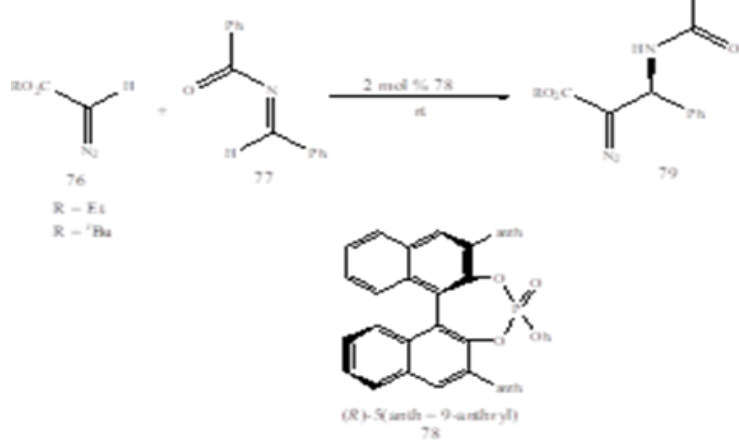

(Scheme 20)

Cross-coupling reactions of arenes to construct biaryls, [216-218], Such reactions have been deemed to be among the most 'aspirational' reactions as yet underdeveloped in the 'key green chemistry research areas' favoured by the pharmaceutical industry. Recently, cross-coupling of aromatic $\mathrm{C}-\mathrm{H}$ bond was carried out by the combination of $\mathrm{Co}(\mathrm{acac}) 3$ and 1,10-phenanthroline (L1, L2, L3, L4) in the presence of KOt-Bu (as a base) as most efficient conversion of 80 occurred, and product 82 could be isolated in $71 \%$ yield $[219,220]$. (Scheme 21)

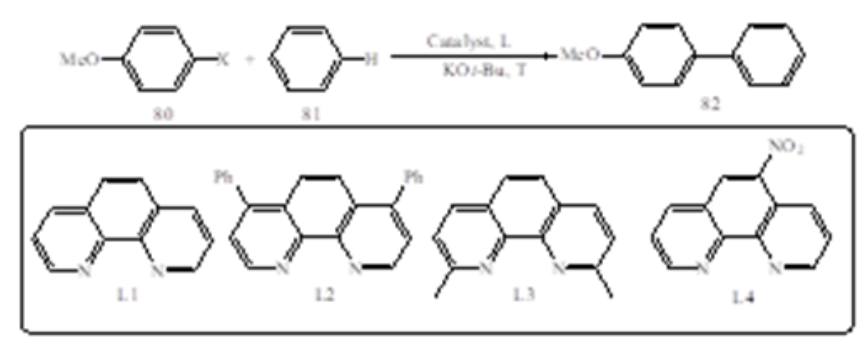

\begin{tabular}{|c|c|c|c|c|c|}
\hline Entry & $\mathbf{X}$ & Co (10 mol \%) & L (mol\%) & $\mathbf{T}\left({ }^{\square} \mathbf{C}\right)$ & Yiled \% \\
\hline 1 & I & $\mathrm{Co}(\mathrm{acac})_{3}$ & DMEDA (40) & 80 & 69 \\
\hline 2 & I & $\mathrm{Co}(\text { acac })_{3}$ & L1 (40) & 80 & 71 \\
\hline 3 & $\mathrm{Br}$ & $\mathrm{Co}(\mathrm{acac})_{3}$ & $\mathbf{L 1}(40)$ & 80 & 70 \\
\hline 4 & $\mathrm{I}$ & - & L1 (40) & 80 & 62 \\
\hline 5 & $\mathrm{Br}$ & - & L1 (40) & 80 & 5 \\
\hline 6 & I & - & L1 (20) & 100 & 83 \\
\hline 7 & $\mathrm{Br}$ & - & L1 (20) & 100 & 48 \\
\hline 8 & $\mathrm{Br}$ & - & L1 (40) & 100 & 87 \\
\hline 9 & $\mathrm{Br}$ & - & DMEDA (40) & 100 & 0 \\
\hline 10 & $\mathrm{Br}$ & - & L2 (40) & 100 & 92 \\
\hline 11 & $\mathrm{Br}$ & - & L3 (40) & 100 & 59 \\
\hline 12 & $\mathrm{Br}$ & - & L4 (40) & 100 & 0 \\
\hline 13 & I & - & L1 (5) & $\begin{array}{l}100 \\
(48 \mathrm{~h})\end{array}$ & 80 \\
\hline
\end{tabular}

(Scheme 21)

Shibasaki's group used the dinuclear nickel catalytic system for the efficient asymmetric vinylogous Mannich reaction and Michael reaction in 2010, [221], many studies have investigated the reaction of $\alpha, \beta$-unsaturated $\gamma$-butyrolactam and various electrophiles. Most of the reactions occurred at the $\gamma$-position of $\alpha, \beta$-unsaturated $\gamma$-butyrolactam [221-223]. Recently, $\alpha, \beta$-unsaturated $\gamma$-butyrolactam 83 could react smoothly with various aromatic-substituted 
tetrahydroisoquinolines 84 in the presence of numerous of organocatalysis compounds (metal free) to generate the desired products in good yields and good to excellent enantioselectivities [224-226]. (Scheme 22)

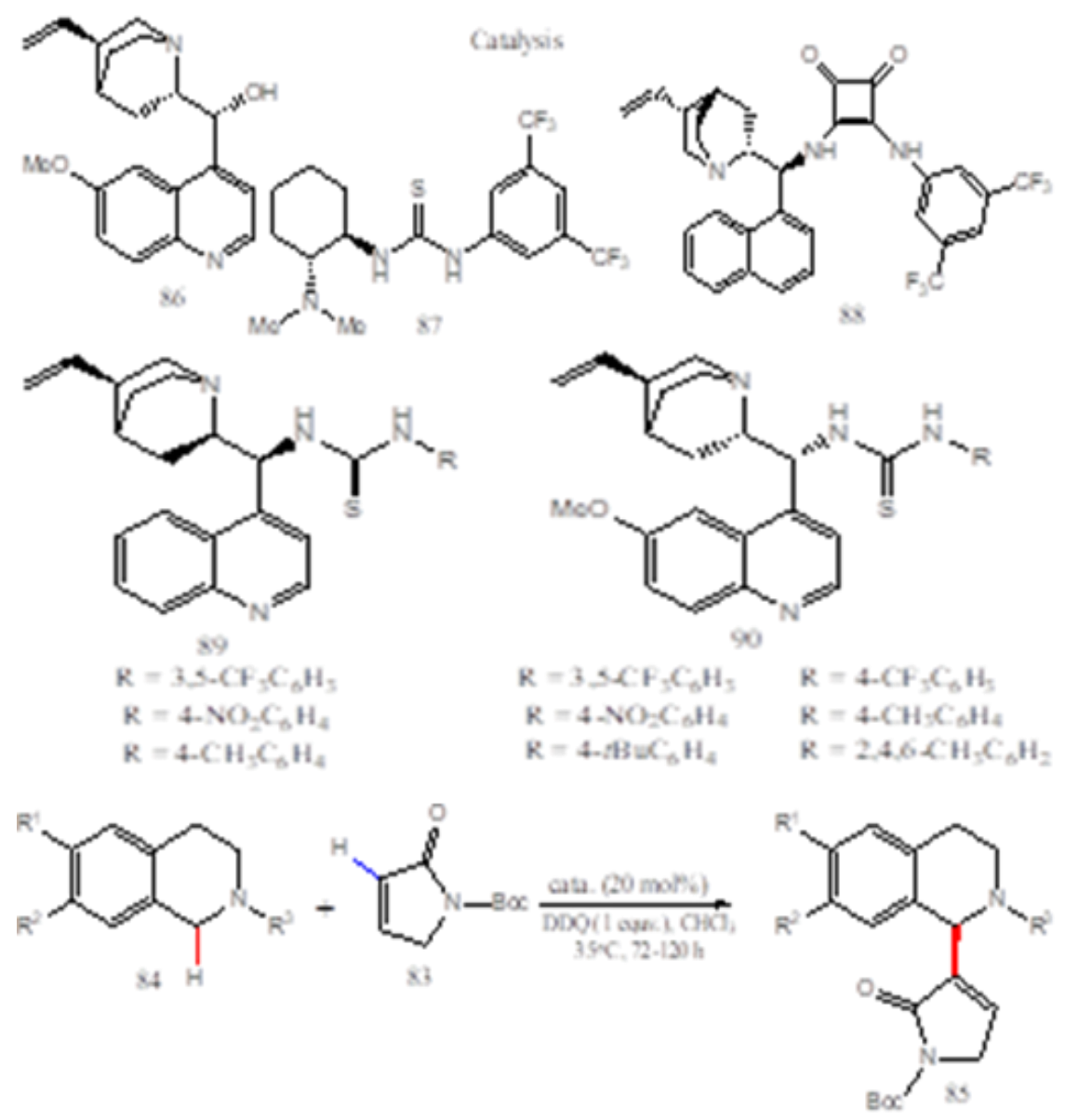

(Scheme 22)

There are some reports in the computational studies focusing on homoenolate as well as umpolung type NHC catalysis, [227-229], no reports have been available on the mechanism of this new form of NHC reactivity leading to $\beta-\mathrm{C}-\mathrm{H}$ functionalization. Raghavan group have some reports in the mechanistic insights into NHC-catalyzed reactions $[230,231]$. Asymmetric NHC-catalyzed $\beta-C-H$ functionalization was reported by Raghavan B. Sunoj and co-worker to investigate the reaction mechanism by using density functional theory computational methods [232]. The mechanism involved in NHC-catalyzed direct $\beta$-C-H activation of saturated carboxylic esters leading to the formation of $\gamma$-lactams (Scheme 23). The description focused on the most preferred pathway identified on the basis of the computed Gibbs free energies at the SMDEtOAc/B3LYP-D2/6-31G** level of theory. 

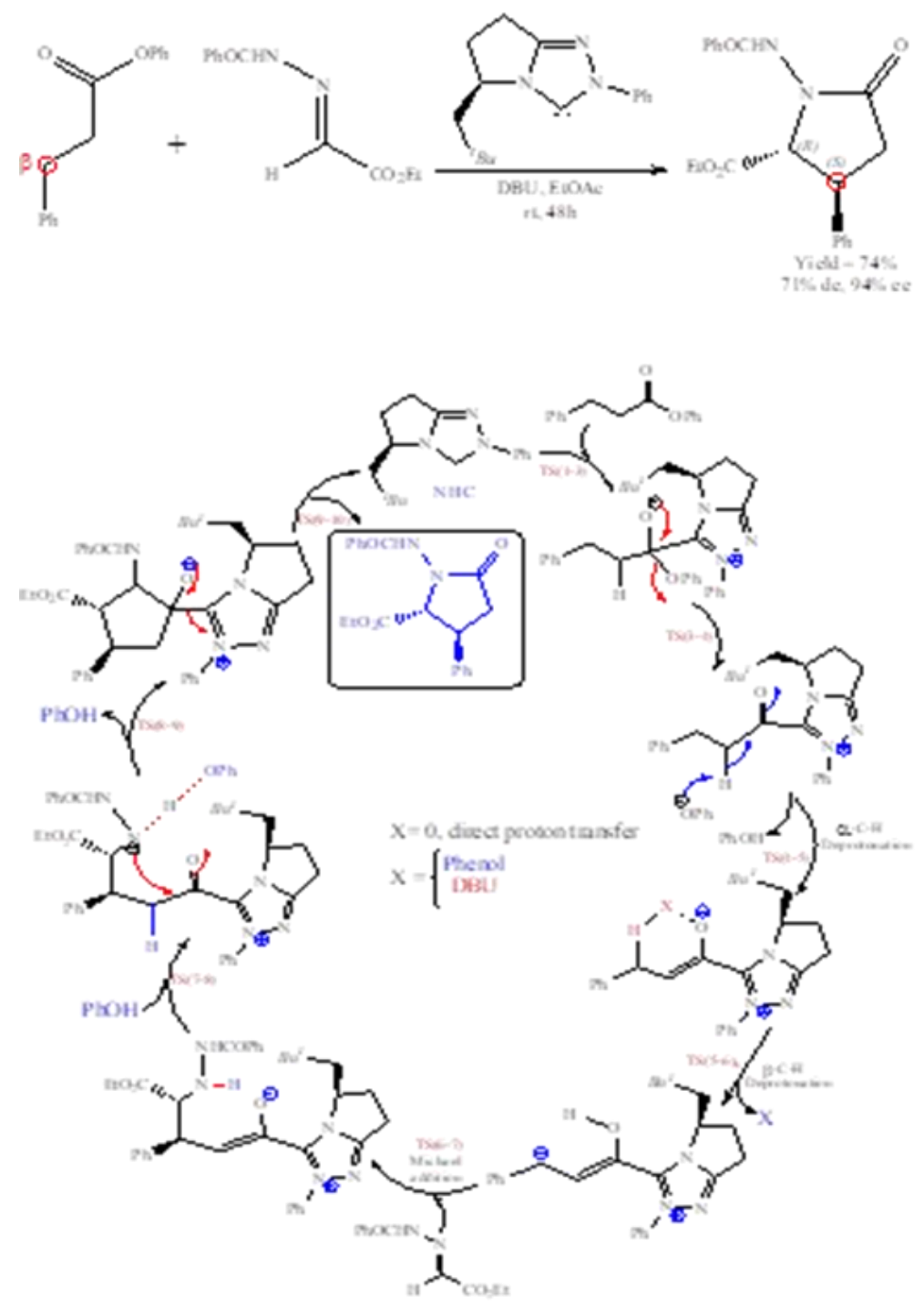

(Scheme 23)

\section{Compliance with ethical standards}

\section{Acknowledgments}

The authors gratefully acknowledge the National Research Centre (NRC), Egypt, for funding this work

\section{Disclosure of conflict of interest}

The authors declare that there is no conflict of interests regarding the publication of this paper

\section{References}

[1] Ullmann F, Bielecki J, Ueber Synthesen in der Biphenylreihe. J. Chem. Ber., 1901; 34, 2174-2185.

[2] Otto Dimroth, Ueber die Mercurirung aromatischer Verbindungen, der deutschen chemischen Gesellschaft. 1902; 35(2): 2032-2045.

[3] Otto Dimroth, Directe Einführung von Quecksilber in aromatische Verbindungen, Berichte der deutschen chemischen Gesellschaft. 1898; 31(2): 2154-2156.

[4] Jones WD, Feher FJ. Comparative reactivities of hydrocarbon carbon-hydrogen bonds with a transition-metal complex. Acc. Chem. Res. 1989; 22(3): 91-100. 
[5] Labinger JA, Bercaw JE. Understanding and exploiting C-H bond activation. Nature. 2002; 417, 507-514.

[6] Dyker G, Handbook of C-H Transformations: Applications in Organic Synthesis. 2005; Wiley-VCH.

[7] Godula K, Sames D. C-H bond functionalization in complex organic synthesis. Science, 2006; 312(5770): 67-72.

[8] Bergman RG. Organometallic chemistry: C-H activation. Nature, 2007; 446, 391-393.

[9] Fagnou K, Lautens M. Rhodium-catalyzed carbon-carbon bond forming reactions of organometallic compounds. Chem. Rev. 2003; 103, 169-196.

[10] Kuninobu Y, Nishina Y, Takeuchi T, Takai, K. Manganese-catalyzed insertion of aldehydes into a C-H bond. Angew. Chem. Int. Ed., 2007; 46, 6518-6520.

[11] Waltz KM, Hartwig JF. Selective functionalization of alkanes by transition-metal boryl complexes. Science, 1997; 277(5323), 211-213.

[12] Chen H, Schlecht S, Semple TC, Hartwig JF. Thermal, catalytic, regiospecific functionalization of alkanes. Science. 2000; 287(5460), 1995-1997.

[13] Cho J-Y, Tse MK, Holmes D, Maleczka RE Jr, Smith MR III. Remarkably selective iridium catalysts for the elaboration of aromatic C-H bonds. Science, 2002, 295, 305-308.

[14] Naota T, Takaya H, Murahashi S.-I. Ruthenium-catalyzed reactions for organic synthesis. Chem. Rev., 1998; 98, $2599-2660$.

[15] Lersch M, Tilset M. Mechanistic aspects of C-H activation by Pt complexes. Chem. Rev., 2005; 105, 2471-2526.

[16] Li Z, Brouwer C, He C. Gold-catalyzed organic transformations. Chem. Rev., 2008; 108, 3239-3265.

[17] Chen X, Hao X-S, Goodhue CE, Yu J-Q. Cu(II)-catalyzed functionalizations of aryl C-H bonds using $\mathrm{O}$ as an oxidant, J. Am. Chem. Soc., 2006; 128, 6790-6791.

[18] Phipps RJ, Grimster NP, Gaunt MJ. Cu(II)-catalyzed direct and site selective arylation of indoles under mild conditions. J. Am. Chem. Soc., 2008; 130, 8172-8174.

[19] Brasche G, Buchwald SL. C-H functionalization/C-N bond formation: copper-catalyzed synthesis of benzimidazoles from amidines. Angew. Chem. Int. Ed., 2008; 47, 1932-1934.

[20] Ueda S, Nagasawa H. Synthesis of 2-arylbenzoxazoles by copper-catalyzed intramolecular oxidative C-O coupling of benzanilides. Angew. Chem. Int. Ed., 2008; 47, 6411-6413.

[21] Xu L-M, Li B-J, Yang Z, Shi Z-J. Organopalladium(IV) chemistry. Chem. Soc. Rev., 2010; 39, 712-733.

[22] Phipps RJ, Gaunt MJ. A meta-selective copper-catalyzed C-H bond arylation. Science, 2009; 323, 1593-1597.

[23] Davies HML, Beckwith REJ. Catalytic enantioselective C-H activation by means of metal-carbenoid-induced C-H insertion. Chem. Rev., 2003; 103, 2861-2904.

[24] Diaz-Requejo MM, Perez PJ, Coinage metal catalyzed C-H bond functionalization of hydrocarbons. Chem. Rev., 2008; 108(8) 3379-3394.

[25] Doyle MP, Duffy R, Ratnikov M, Zhou L, Catalytic Carbene Insertion into C-H Bonds. Chem. Rev., 2010; 110, 704724.

[26] Sun C-L, Li B-J, Shi Z-J, Pd-catalyzed oxidative coupling with organometallic reagents via C-H activation. Chem. Commun, 2010; 46, 677-685.

[27] Uyanik M, Okamoto H, Yasui T, and Ishihara K. Quaternary ammonium (hypo)iodite catalysis for enantioselective oxidative cycloetherification. Science, 2010; 328(5984): 1376-9.

[28] Mai W-P, Wang H-H , Li Z-C , Yuan J-W, Xiao Y-M, Yang L-R, Mao P and Qu L-B. nBu4NI-catalyzed direct synthesis of $\alpha$-ketoamides from aryl methyl ketones with dialkylformamides in water using TBHP as oxidant, Chem. Commun., 2012; 48, 10117-10119.

[29] Uyanik M, Suzuki D, Yasuiand TK Ishihara. In situ generated (hypo)iodite catalysts for the direct $\alpha$-oxyacylation of carbonyl compounds with carboxylic acids. Angew. Chem., Int. Ed., 2011; 50,5331

[30] Wei W, Zhang C, Xu Y and Wan X B. Synthesis of tert-butyl peresters from aldehydes by Bu4NI-catalyzed metalfree oxidation and its combination with the Kharasch-Sosnovsky reaction. Chem. Commun., 2010; 47, 10827 
World Journal of Advanced Research and Reviews, 2021, 09(01), 001-030

[31] Froehr T, Sindlinger CP, Kloeckner U, Finkbeiner P, Nachtsheim BJ. A Metal-Free Amination of Benzoxazoles -The First Example of an Iodide-Catalyzed Oxidative Amination of Heteroarenes, Org. Lett., 2011; 13, 3754

[32] Ma L, Wang X, Yu W and Han B. TBAI-catalyzed oxidative coupling of aminopyridines with $\beta$-keto esters and 1,3diones-synthesis of imidazo[1,2-a]pyridines, Chem. Commun., 2011; 47,11333.

[33] Richardson RD and Wirth T. Hypervalent iodine goes catalytic, Angew. Chem. Int. Ed., 2006; 45, 4402

[34] Zhdankin VV and Stang PJ. Chemistry of Polyvalent Iodine. Chem. Rev., 2008; 108,5299

[35] Dohi T and Kita Y. Hypervalent iodine reagents as a new entrance to organocatalysts, Chem. Commun., 2009; 16, 2073-2085.

[36] Hari DP, Koenig B, Synthetic applications of eosin Y in photoredox catalysis. Chem Commun, 2014; 50, 6688.

[37] Xi Y, Yi H, Lei A, Synthetic applications of photoredox catalysis with visible light, Org. Biomol. Chem., 2013; 11, 2387.

[38] Zeitler K. Photoredox Catalysis with Visible Light, Angew. Chem., Int. Ed., 2009; 48, 9785.

[39] Yoon TP, Ischay MA, Du J. Visible light photocatalysis as a greener approach to photochemical synthesis, J. Nat. Chem., 2010; 2, 527-532.

[40] Narayanam JMR, Stephenson CR. Visible light photoredox catalysis: applications in organic synthesis. J. Chem. Soc. Rev., 2011; 40, 102.

[41] Teply FC. Photoredox catalysis by $\left[\mathrm{Ru}(\mathrm{bpy})_{3}\right]^{2+}$ to trigger transformations of organic molecules. Organic synthesis using visible-light photocatalysis and its 20th century roots. Czech. Chem. Commun., 2011; 76(7), 859-917.

[42] Xuan J, Xiao W-J. Visible-light photoredox catalysis. Angew. Chem., Int. Ed., 2012; 51, 6828.

[43] Ravelli D, Fagnoni M, Albini A. Photoorganocatalysis. What for? Chem. Soc. Rev., 2013; 42(1), 97-113.

[44] Schultz DM, Yoon TP, 2014, Solar synthesis: prospects in visible light photocatalysis. Science, 2014; 343 , 985.

[45] Prier CK, Rankic DA, MacMillan DWC. Visible light photoredox catalysis with transition metal complexes: applications in organic synthesis. Chem. Rev., 2013; 113, 5322.

[46] Tucker JW, Stephenson CRJ. Shining Light on Photoredox Catalysis: Theory and Synthetic Applications, J. of Org. Chem., 2012; 77(4), 1617-1622.

[47] Collman de-Jp, Hegedus LS, Norton JR, Finke RC, Principles and Applications of Organotransition Metal Chemistry (Inglés) Tapa dura - 1 junio 1987, (University Science Books, U.S.; 2 ${ }^{\text {nd }}$ Revised edition), 279-354.

[48] Hill CL, John Ed, Activation and Functionalization of Alkanes, (Wiley \& Sons, Interscience, New York), 1989, 151194.

[49] Scheldon R.A, 1981, Metal catalyzed Oxidations of organic compounds: mechanistic principles and synthetic methodology including biochemical processes (Academic press, new York) 1981; 446.

[50] Yu,J-Q, Giri R, and Chen X. $\sigma$-Chelation-directed C-H functionalizations using Pd(II) and Cu(II) catalysts: regioselectivity, stereoselectivity and catalytic turnover. Org. Biomol. Chem., 2006; 4, 4041-4047.

[51] Chen X, Hao X-S, Goodhue $\mathrm{CE}$, and $\mathrm{Yu} \mathrm{J}-\mathrm{Q}, \mathrm{Cu}(\mathrm{II})$-Catalyzed Functionalizations of Aryl C-H Bonds Using $\mathrm{O}_{2}$ as an Oxidant, J. Am. Chem. Soc., 2006; 128(21), 6790-6791.

[52] Xu L-L, Wang X, Ma B, Yin M-X, Lin H-X, Dai H-X and Yu J-Q, Copper mediated C-H amination with oximes: en route to primary anilines. Chem. Sci., 2018; 9, 5160.

[53] Ueda S and Nagasawa H. Synthesis of 2-Arylbenzoxazoles by Copper-Catalyzed Intramolecular Oxidative CO Coupling of Benzanilides. Angew. Chem. Int. Ed., 2008; 47, 6411 -6413.

[54] Lin M, Hogan T and Sen A. Highly Catalytic Bimetallic System for the Low-Temperature Selective Oxidation of Methane and Lower Alkanes with Dioxygen as the Oxidant. J. Am. Chem. Soc., 1997;119, 6048-6053.

[55] Zhao J, Wang Y, He Y, Liu L, and Zhu Q, Cu-Catalyzed Oxidative C(sp)-H Cycloetherification of oArylphenols for the Preparationof Dibenzofurans. Org. Lett., 2012; 14 (4), 1078-1081.

[56] Shaabani A, Mirzaei P, Naderi S, Lee DG, Green oxidations. The use of potassium permanganate supported on manganese dioxide, Tetrahedron, 2004; 60, 11415-11420. 
[57] Rathore R, Saxena N, Chandrasekaran S, Convenient Method of Benzylic Oxidation with Pyridinium Chlorochromate. Synth. Commun., 1986; 16, 1493-1498.

[58] European chemicals agency (ECHA) website. http://echa.europa.eu/web/guest/regulations/reach/legislation.

[59] Sterckx H, Houwer JD, Mensch C, Herrebout W, Tehrani KA and Maes BUW, Base metal-catalyzed benzylic oxidation of (aryl)(heteroaryl)methanes with molecular oxygen. Beilstein J. Org. Chem., 2016; 12, 144-153.

[60] Zhao J, Zhang Q, Liu L, He Y, Li J, Li J, and Zhu Q, CuI-Mediated Sequential Iodination/Cycloetherification of oArylphenols: Synthesis of 2- or 4-Iododibenzofurans and Mechanistic Studies. Org. Lett., 2012; 14(20):53625365.

[61] Huang X, Li X, Zou M, Song S, Tang C, Yuan Y and Jiao N, From Ketones to Esters by a Cu-Catalyzed Highly Selective C(CO)-C(alkyl) Bond Cleavage: Aerobic Oxidation and Oxygenation with Air. J. Am. Chem. Soc., 2014; 136(42), 14858-14865.

[62] Huang X, Li X, Zou M, Pan J and Jiao N, TEMP and copper cocatalyzed oxygenation of ketones with molecular oxygen: chemoselective synthesis of $\alpha$-ketoesters. Org. Chem. Front., 2015; 2, 354-359.

[63] Pintori DG and Greaney M F, Intramolecular Oxidative C-H Coupling for Medium-Ring Synthesis. J. Am. Chem. Soc., 2010; 133, 1209-1211.

[64] Zhao L, Li Z, Chang L, Xu J, Yao H and Wu X, Efficient Construction of Fused Indolines with a 2-Quaternary Center via an Intramolecular Heck Reaction with a Low Catalyst Loading. Org. Lett., 2012; 14, 2066-2069.

[65] Shen C, Liu R-R, Fan R-J, Li Y-L, Xu T-F, Gao J-R and Jia Y-X, Enantioselective Arylative Dearomatization of Indoles via Pd-Catalyzed Intramolecular Reductive Heck Reactions. J. Am. Chem. Soc., 2015; 137, 4936.

[66] Petrone DA., Yen A, Zeidan N and Lautens M, Dearomative Indole Bisfunctionalization via a Diastereoselective Palladium-Catalyzed Arylcyanation. Org. Lett., 2015; 17, 4838-4841

[67] Gao S, Yang C, Huang Y, Zhao L, Wu X, Yao H and Lin A. J. Name., 2013; 1-3.

[68] Webb ME, Marquet A, Mendel R R, Rebeille F, Smith AG. Elucidating biosynthetic pathways for vitamins and cofactors. Nat. Prod. Rep., 2007; 24, 988.

[69] Kim J, Movassaghi M. Biogenetically inspired syntheses of alkaloid natural products. Chem. Soc. Rev., 2009; 38(11), 3035-3050.

[70] Bagley MC, Dale JW, Merritt EA, Xiong X, Thiopeptide antibiotics. Chem. Rev., 2005; 105(2), 685-714.

[71] Mishra A, Ma C-Q, Bauerle P, Functional Oligothiophenes: Molecular Design for Multidimensional Nanoarchitectures and Their Applications. Chem. Rev., 2009; 109, 1141.

[72] Wang X, Sun K, Lv Y, Ma F, Li G, Li D, Zhu Z, Jiang Y, and Zhao F, Regioselective CH Imidation of Five-Membered Heterocyclic Compounds through a Metal Catalytic or Organocatalytic Approach, Chem. Asian J., 2014; 9,3413 3416

[73] Chan DMT, Monaco KL, Wang RP, Winters MP, New N- and O-arylations with phenylboronic acids and cupric acetate, Tetrahedron Lett., 1998; 39, 2933-2936.

[74] Lam PYS, Clark CG, Saubern S, Adams J, Winters MP, Chan DMT, Combs A. New aryl/heteroaryl C-N bond crosscoupling reactions via arylboronic acid/cupric acetate arylation. Tetrahedron Lett., 1998; 39, 2941-2944.

[75] Evans DA, Katz JL, WestR. Synthesis of Diaryl Ethers through the Copper-Promoted Arylation of Phenols with Arylboronic Acids. An Expedient Synthesis of Thyroxine, Tetrahedron Lett., 1998,39, 2937-2940.

[76] Hamada T, Ye X, Stahl SS. Copper-Catalyzed Aerobic Oxidative Amidation of Terminal Alkynes: Efficient Synthesis of Ynamides. J. Am. Chem. Soc., 2008; 130, 833-835.

[77] Balsamo A, Macchia B, Macchia F, Rossello A, Domiano P. 3-(4-iodomethyl-2-oxo-1-azetidinyl) propynoic acidtbutyl ester: a new $\beta$-lactam derivative, synthesis of an ynamide by reaction of 4-iodomethylazetidin-2-one with the $\boldsymbol{t}$-butyl ester of propiolic acid in the presence of copper(i), Tetrahedron Lett., 1985; 26, 4141-4144.

[78] King AE, Brunold TC, Stahl SS, N-i-Propoxy-N-biphenyl sulfonylaminobutylhydroxamic acids as potent and selective inhibitors.of MMP-2 and MT1-MMP. J. Am. Chem. Soc., 2009,131, 5044-5045.

[79] Chen X, Hao X-S, Goodhue CE, Yu J-Q, Cu(II)-catalyzed functionalizations of aryl C-H bonds using $\mathrm{O}_{2}$ as an oxidant, J. Am. Chem. Soc., 2006; 128, 6790-6791. 
[80] Uemura T, Imoto S, Chatani N, Amination of the Ortho C-H Bonds by the Cu(OAc) 2-mediated Reaction of 2Phenylpyridines with Anilines. Chem. Lett., 2006; 35, 842-843.

[81] Brasche G, Buchwald SL, C-H functionalization/C-N bond formation: copper-catalyzed synthesis of benzimidazoles from amidines. Angew. Chem., Int. Ed., 2008; 47, 1932-1934.

[82] Thu H-Y, Yu W-Y, Che C-M. Intermolecular Amidation of Unactivated $\mathrm{sp}^{2}$ and $\mathrm{sp}^{3} \mathrm{C}-\mathrm{H}$ Bonds via PalladiumCatalyzed Cascade C-H Activation/Nitrene Insertion, J. Am. Chem. Soc., 2006; 128, 9048-9049.

[83] Wasa M, Yu J-Q, Synthesis of $\beta-, \gamma-$, and $\delta$-Lactams via Pd(II)-Catalyzed C-H Activation Reactions. J. Am. Chem. Soc., 2008; 130, 14058-14059.

[84] Inamoto K, Hasegawa C, Hiroya K, Doi T. Palladium-Catalyzed Synthesis of 2-Substituted Benzothiazoles via a C-H Functionalization/ Intramolecular C-S Bond Formation Process. Org. Lett., 2008; 10, 5147-5150.

[85] Jordan-Hore JA, Johansson CCC, Gulias M. Beck EM, Gaunt MJ, Oxidative Pd(II)-Catalyzed C-H Bond Amination to Carbazole at Ambient Temperature, J. Am. Chem. Soc., 2008; 130, 16184-16186.

[86] Ueda S, Nagasawa H. Synthesis of 2-arylbenzoxazoles by copper-catalyzed intramolecular oxidative C-0 coupling of benzanilides. Angew. Chem., Int. Ed., 2008; 47, 6411-6413.

[87] Mei T-S, Wang X, Yu J-Q, Pd(II)-Catalyzed Amination of C-H Bonds Using Single-Electron or Two-electron Oxidants. J. Am. Chem. Soc., 2009; 131, 10806-10807.

[88] Wang Q and Schreiber SL, Copper-Mediated Amidation of Heterocyclic and Aromatic C-H Bonds, Org. Lett., 2009; 11(22), 5178-5180.

[89] Nozawa-Kumada K, Kadokawa J, Kameyama T, and Kondo Y, Copper-Catalyzed sp3 C-H Aminative Cyclization of 2-Alkyl-N-arylbenzamides: An Approach for the Synthesis of N-Arylisoindolinones. Org. Lett., 2015; 17(18):4479-4481.

[90] Heacock JF, Edmison MT, Orientation and Relative Reaction Rate Factors in Aromatic Substitution by the Benzenesulfonimido Radical, J. Am. Chem. Soc., 1960; 82, 3460.

[91] Lim Y-G, Kang J-B and Kim Y, Regioselective alkylation of 2-phenylpyridines with terminal alkenes via C-H bond activation by a rhodium catalyst. J. Chem. SOC.-Perkin Transactions 1, 1996; 2201-2206.

[92] Pateland P, Chang S, Cobalt(III)-Catalyzed C-H Amidation of Arenes using Acetoxycarbamates as Convenient Amino Sources under Mild Conditions. ACS Catal., 2015; 5(2), 853-858.

[93] Giri R, Shi B-F, Engle KM, Maugel N, Yu J-Q, Transition metal-catalyzed C-H activation reactions: diastereoselectivity and enantioselectivity. Chem. Soc. Rev., 2009; 38, 3242.

[94] Affron DP, Davis OA, Bull JA. Regio- and Stereospecific Synthesis of C-3 Functionalized Proline Derivatives by Palladium Catalyzed Directed C( $\left.\mathrm{sp}^{3}\right)-\mathrm{H}$ Arylation. Org. Lett., 2014; 16, 4956.

[95] Li Z, Zhang Y, Zhang L, Liu Z-Q. Free-Radical Cascade Alkylarylation of Alkenes with Simple Alkanes: Highly Efficient Access to Oxindoles via Selective $\left(\mathrm{sp}^{3}\right) \mathrm{C}-\mathrm{H}$ and $\left(\mathrm{sp}^{2}\right) \mathrm{C}-\mathrm{H}$ Bond Functionalization. Org. Lett., 2014; 16, 382.

[96] Monir K, Bagdi AK, Ghosh M, Hajra A, Regioselective oxidative trifluoromethylation of imidazoheterocycles via $\mathrm{C}\left(\mathrm{sp}^{2}\right)-\mathrm{H}$ bond functionalization. J. Org. Chem., 2015; 80, 1332.

[97] Su Y, Zhou HH, Chen J, Xu J, Wu X, Lin A, Yao H, Solvent-Controlled Switchable C-H Alkenylation of 4-Aryl-1Hpyrrole-3-carboxylates: Application to the Total Synthesis of ( \pm )-Rhazinilam. Org. Lett., 2014; 16, 4884.

[98] Yamaguchi AD, Chepiga KM, Yamaguchi J, Itami K, Davies HML, Concise Syntheses of Dictyodendrins A and F by a Sequential C-H Functionalization Strategy. J. Am. Chem. Soc., 2015; 137(2), 644.

[99] Iaroshenko VO, Gevorgyan A, Davydova O, Villinger A, Langer P, Regioselective and Guided C-H Activation of 4Nitropyrazoles, J. Org. Chem., 2014; 79, 2906.

[100] Bon JL, Feng D, Marder SR, Blakey SB, C-H Functionalization Protocol for the Direct Synthesis of Benzobisthiazole Derivatives. J. Org. Chem., 2014; 79, 7766-7771.

[101] Kleiman JP, Dubeck M. The Preparation of Cyclopentadienyl [o-(Phenylazo) Phenyl]Nickel. J. Am. Chem. Soc., 1963; 85, 1544. 
[102] Shiota H, Ano Y, Aihara Y, Fukumoto Y, and Chatani N. Nickel-Catalyzed Chelation-Assisted Transformations Involving Ortho $\mathrm{C}-\mathrm{H}$ Bond Activation: Regioselective Oxidative Cycloaddition of Aromatic Amides to Alkynes. J. Am. Chem. Soc., 2011; 133, 14952-14955.

[103] Barsu N, Sen M, Premkumar JR and Sundararaju B. Cobalt (III) catalyzed C-8 selective C-H and C-O coupling of quinoline $\mathrm{N}$-oxide with internal alkynes via $\mathrm{C}-\mathrm{H}$ activation and oxygen atom transfer. Chem. Commun., 2016; 52(7), 1338-1341.

[104] Li M and Kwong FY, Cobalt-Catalyzed Tandem C-H Activation/C-C Cleavage/C-H Cyclization of Aromatic Amides with Alkylidene cyclopropanes, Angew. Chem. Int. Ed., 2018; 57, 6512 -6516.

[105] Chen L, Shi E, Liu ZJ, Chen S, Wei W, Li H, Xu K and Wan X B. nBu4NI-catalyzed direct synthesis of $\alpha$-ketoamides from aryl methyl ketones with dialkylformamides in water using TBHP as oxidant Chem.-Eur. J., 2011; 17, 4085

[106] Uyanik M, Suzuki D, Yasui T and Ishihara K, In situ generated (hypo)iodite catalysts for the direct $\alpha$-oxyacylation of carbonyl compounds with carboxylic acids. Angew. Chem., Int. Ed., 2011; 50, 5331-5334

[107] Wei W, Zhang C, Xu Y and Wan XB. Synthesis of tert-butyl peresters from aldehydes by Bu4NI-catalyzed metalfree oxidation and its combination with the Kharasch-Sosnovsky reaction, Chem. Commun., 2011; 47, 10827.

[108] Froehr T, Sindlinger CP, Kloeckner U, Finkbeiner P, and Nachtsheim BJ, A Metal-Free Amination of Benzoxazoles -The First Example of an Iodide-Catalyzed Oxidative Amination of Heteroarenes. Org. Lett., 2011; 13, 3754-3757.

[109] Ma L, Wang X, Yu W, Han B. TBAI-catalyzed oxidative coupling of aminopyridines with $\beta$-keto esters and 1,3diones-synthesis of imidazo[1,2-a]pyridines. Chem Commun, 2011; 47,11333 -11335.

[110] Bowne DM, Degraw JI, Shah VR, Bonner WA. The Synthesis and Pharmacological Action of Tremetone. J. Med. Chem., 1963; 6, 315-9.

[111] Banskota AH, Tezuka Y, Prasain JK, Matsushige K, Saiki I, Kadota S, Chemical Constituents of Brazilian Propolis and Their Cytotoxic Activities. J. Nat. Prod., 1998; 61, 896.

[112] Céspedes CL, Uchoa A, Salazar JR, Perich F, Pardo F. Plant Growth Inhibitory Activity of p-Hydroxyacetophenones and Tremetones from Chilean Endemic Baccharis Species and Some Analogous: A Comparative Study, J. Agric. Food Chem., 2002; 50(8), 2283-2292.

[113] Shi GQ. Novel 2,3-dihydrobenzofuran-2-carboxylic acids: highly potent and subtype-selective PPARalpha agonists with potent hypolipidemic activity, J. Med. Chem., 2005; 48(17), 5589-5599.

[114] Chu G-H, Potent and highly selective kappa opioid receptor agonists incorporating chroman- and 2,3dihydrobenzofuran-based constraints, Bioorg. Med. Chem. Lett., 2005; 15(23), 5114.

[115] Cohen JL, Limon A, Miledi R, Chamberlin AR. Design, synthesis, and biological evaluation of a scaffold for iGluR ligands based on the structure of (-)-dysiherbaine, Bioorg. Med. Chem. Lett., 2006; 16(8), 2189.

[116] Ito C, Isoflavonoids with Antiestrogenic Activity from Millettia pachycarpa, J. Nat. Prod. 2006; 69, $138-141$.

[117] Duan JA, Wang L, Qian S, Su S, Tang Y, A New Cytotoxic Prenylated Dihydrobenzofuran Derivative and Other Chemical Constituents from the Rhizomes of Atractylodes lancea DC, Arch. Pharm. Res., 2008; 31(8), 965.

[118] Wirth T, Ed., Hypervalent Iodine Chemistry (Topics in Current Chemistry) (Springer, Berlin), 2003 , vol. 224.

[119] Zhdankin VV, Stang PJ. Chemistry of Polyvalent Iodine, Chem. Rev., 2008; 108(12), 5299.

[120] Lv Y, Sun K, Wang T, Li G, Pu W, Chai N, Shen H, and Wu Y. n-Bu 4 NI-catalyzed intermolecular C-O cross-coupling reactions: synthesis of alkyloxyamines. RSC Adv., 2015; 5, 72142.

[121] Xie J, Jiang H, ChengY and Zhu C. Metal-free, organocatalytic cascade formation of C-N and C-O bonds through dual sp ${ }^{3} \mathrm{C}-\mathrm{H}$ activation: oxidative synthesis of oxazole derivatives, Chem. Commun., 2012; 48, 979-981.

[122] A book on cascade reactions: Tietze LF, Brasche G and Gericke K, Domino Reactions in Organic Synthesis, 2006,Wiley-VCH, Weinheim.

[123] Uyanik M, Okamoto H, Yasui T and Ishihara K. Quaternary ammonium (hypo)iodite catalysis for enantioselective oxidative cycloetherification, Science, 2010; 328, 1376.

[124] Ciriminna R, Pagliaro M, Industrial Oxidations with Organocatalyst TEMPO and Its Derivatives. Org. Process Res. Dev., 2010;14, 245.

[125] Tebben L, Studer A, Applications in Synthesis and in Polymer Chemistry. Angew. Chem., Int. Ed., $2011 ; 50,5034$. 
[126] Wertz S, Studer A, Nitroxide-catalyzed transition-metal-free aerobic oxidation processes. Green Chem., 2013; 15, 3116.

[127] Ryland BL, Stahl SS. Practical aerobic oxidations of alcohols and amines with homogeneous copper/TEMPO and related catalyst systems. Angew. Chem., Int. Ed., 2014; 53, 8824.

[128] Cao Q, Dornan LM, Rogan L, Hughes LN, Muldoon M. Aerobic oxidation catalysis with stable radicals. J. Chem. Commun., 2014; 50, 4524.

[129] Shibuya M, Tomizawa M, Suzuki I, Iwabuchi Y. 2-Azaadamantane N-Oxyl (AZADO) and 1-Me-AZADO: Highly Efficient Organocatalysts for Oxidation of Alcohols. J. Am. Chem. Soc., 2006; 128(26), 8412.

[130] Graetz B, Rychnovsky S, Leu W-H, Farmer P, Lin R. $C_{2}$-Symmetric nitroxides and their potential as enantioselective oxidants. Tetrahedron: Asymmetry. Tetrahedron, 2005; 16, 3584-3598.

[131] Amar M, Bar S, Iron MA, Toledo H, Tumanskii B, Shimon LJW, Botoshansky M, Fridman N, Szpilman A M. Design concept for $\alpha$-hydrogen-substituted nitroxides. Nat. Commun., 2015; 6, 6070.

[132] Shibuya M, Sato T, Tomizawa M, Iwabuchi Y. Oxoammonium salt/NaClO2: an expedient, catalytic system for onepot oxidation of primary alcohols to carboxylic acids with broad substrate applicability. Chem. Commun., 2009; 1739.

[133] Shibuya M, Shibuta T, Fukuda H, Iwabuchi Y. Organocatalytic One-Pot Oxidative Cleavage of Terminal Diols to Dehomologated Carboxylic Acids, Org. Lett., 2012,14, 5006.

[134] Kim J, Stahl SS, Cu/Nitroxyl-Catalyzed Aerobic Oxidation of Primary Amines into Nitriles at Room Temperature, ACS Catal., 2013; 3, 1652.

[135] Furukawa K., Shibuya M, Yamamoto Y. Chemoselective Catalytic Oxidation of 1,2-Diols to $\alpha$-Hydroxy Acids Controlled by TEMPO-ClO2 Charge-Transfer Complex. Org. Lett., 2015; 17, 2282.

[136] Muramatsu W, Nakano K. Efficient C(sp3)-H Bond Functionalization of Isochroman by AZADOL Catalysis. Org. Lett., 2015; 17, 1549.

[137] Pradhan PP, Bobbitt JM, Bailey WF. Oxidative Cleavage of Benzylic and Related Ethers, Using an Oxoammonium Salt. J. Org. Chem., 2009; 74, 9524.

[138] Zhu X, Wang Y-F, Zhang F- L, Chiba S. TEMPO-Mediated Aliphatic C-H Oxidation with Oximes and Hydrazones. Org. Lett., 2013; 15, 3214.

[139] Wang S-N, Li X.-M, Liu H-W, Xu L, Zhuang J-C, Li J, Li H, Wang W. Organocatalytic Enantioselective Direct Additions of Aldehydes to 4-Vinylpyridines and Electron-Deficient Vinylarenes and Their Synthetic Applications, J. Am. Chem. Soc., 2015; 137, 2303.

[140] Chen J, Li J, Wang J, Li H, Wang W, Guo Y-W. Phosphine-Catalyzed Aza-MBH Reactions of Vinylpyridines: Efficient and Rapid Access to 2,3,5-Triarylsubstituted 3-Pyrrolines. Org. Lett., 2015; 17, 2214.

[141] Song A-G, Zhang X-S, Song X-X, Chen X-B, Yu C-G, Huang H, Li H, Wang W, Construction of Chiral Bridged Tricyclic Benzopyrans: Enantioselective Catalytic Diels-Alder Reaction and a One-Pot Reduction/Acid-Catalyzed Stereoselective Cyclization. Angew. Chem., Int. Ed., 2014; 53, 4940.

[142] Zhang X-S, Song X-X, Li H, Zhang S-L, Chen X-B, Yu X-H, Wang W. An Organocatalytic Cascade Approach toward Polysubstituted Quinolines and Chiral 1,4-Dihydroquinolines-Unanticipated Effect of N-Protecting Groups. Angew. Chem., Int. Ed., 2012; 51, 7282.

[143] Liu R-H, Liang X-M, Dong C-Y, Hu X-Q. Transition-Metal-Free: A Highly Efficient Catalytic Aerobic Alcohol Oxidation Process. J. Am. Chem. Soc., 2004; 126(13), 4112.

[144] Wang X-L, Liu R-H, Jin Y, Liang X-M. TEMPO/HCl/NaNO2 Catalyst: A Transition-Metal-Free Approach to Efficient Aerobic Oxidation of Alcohols to Aldehydes and Ketones Under Mild Conditions. Chem. Eur. J., 2008; 14, 2679.

[145] Zhang Z, Gao Y, Liu Y, Li J, Xie H, Li H, and Wang W.Organocatalytic Aerobic Oxidation of Benzylic sp ${ }^{3}$ C-H Bonds of Ethers and Alkylarenes Promoted by a Recyclable TEMPO Catalyst. Org. Lett., 2015; 17, 5492-5495.

[146] Zhuang Z, Yu C-B, Chen G, Wu Q-F, Hsiao Y, Joe CL, Qiao JX, Poss MA and Yu J-Q. Ligand-Enabled beta-C(sp3)-H Olefination of Free Carboxylic Acids. J. Am. Chem. Soc., 2018; 140, 10363.

[147] Farmer ME, Wang P, Shi H and Yu J-Q, Palladium-Catalyzed meta-C-H Functionalization of Masked Aromatic Aldehydes. ACS Catal., 2018; 8, 7362. 
[148] Shi H, AN H, Shao Y, Shao Q and Yu J-Q, Enantioselective remote meta-C-H arylation and alkylation via a chiral transient mediator. Nature, 2018; 558, 581.

[149] Park H, Verma P, Hong K and Yu J-Q. Controlling Pd(IV) reductive elimination pathways enables Pd(II)-catalysed enantioselective C(sp3)-H fluorination. Nature Chemistry, 2018; 10, 755.

[150] Uyanik M, Okamoto H, Yasui T, Ishihara K. Quaternary ammonium (hypo)iodite catalysis for enantioselective oxidative cycloetherification. Science, 2010; 328, 1376.

[151] Li W., Zhu X., Mao H., Tang Z., Cheng Y., Zhu C., Visible-light-induced direct C( $\left.\operatorname{sp}^{3}\right)-H$ difluromethylation of tetrahydroisoquinolines with the in situ generated difluoroenolates. Chem. Commun., 2014; 50, 7521-7523.

[152] Bergonzini G, Schindler CS, Wallentin C-J, Jacobsen EN, Stephenson CRJ. Photoredox activation and anion binding catalysis in the dual catalytic enantioselective synthesis of $\beta$-amino esters. Chem. Sci., 2014; 5, 112-116

[153] Wang F-F, Luo C-P, Deng G, Yang L. C( $\left.\mathrm{sp}^{3}\right)-\mathrm{C}\left(\mathrm{sp}^{3}\right)$ bond formation via copper/Brønsted acid co-catalyzed C( $\left.\mathrm{sp}^{3}\right)-$ $\mathrm{H}$ bond oxidative cross-dehydrogenative-coupling (CDC) of azaarenes. Green Chem., 2014; 16, 2428-2431

[154] Zhong J-J, Meng Q-Y, Liu B, Li X-B, Gao X-W, Lei T, Wu C-J, Li Z-J, Tung C-H, Wu L-Z. Cross-Coupling Hydrogen Evolution Reaction in Homogeneous Solution without Noble Metals. Org. Lett., 2014; 16, 1988-1991.

[155] Ueda H, Yoshida K, Tokuyama H. Acetic Acid Promoted Metal-Free Aerobic Carbon-Carbon Bond Forming Reactions at $\alpha$-Position of Tertiary Amines. Org. Lett., 2014; 16, 4194-4197

[156] Min C, Sanchawala A, Seidel D. Dual C-H Functionalization of N-Aryl Amines: Synthesis of Polycyclic Amines via an Oxidative Povarov Approach Org. Lett., 2014; 16, 2756-2759

[157] Xiao T., Li L., Lin G., Mao Z., Zhou L., 2014, Metal-Free Visible-Light Induced Cross-Dehydrogenative Coupling of Tertiary Amines with Diazo Compounds, Org. Lett., 16(16), 4232-4235 ;

[158] Feng Z-J, Xuan J, Xia X-D, Ding W, Guo W, Chen J-R, Zou Y-Q, Lu L-Q, Xiao W-J. Direct sp ${ }^{3}$ C-H acroleination of $\boldsymbol{N}$ aryl-tetrahydroisoquinolines by merging photoredox catalysis with nucleophilic catalysis, Org. Biomol. Chem., 2014; 12, 2037-2040

[159] Huo C, Wang Wu CM, Jia X, Wang X, Yuan Y, Xie H. Catalytic amounts of triarylaminium salt initiated aerobic oxidative coupling of $\boldsymbol{N}$-aryl tetrahydroisoquinolines. Org. Biomol. Chem., 2014; 12, 3123-3128.

[160] Muramatsu W., Nakano K., Li C.-J., Direct $\mathrm{sp}^{3} \mathrm{C}-\mathrm{H}$ bond arylation, alkylation, and amidation of tetrahydroisoquinolines mediated by hypervalent iodine(III) under mild conditions. Org. Biomol. Chem., 2014; $12,2189-2192$.

[161] Kong S, Zhang L, Dai X, Tao L, Xie C, Shi L. and Wang M. DDQ-mediated Direct C(sp³)C-H Cyanation of Benzyl Ethers and 1,3-Diarylpropenes under Solvent- and Metal-free Conditions. Adv. Synth. Catal., 2015; 357, 24532456.

[162] Zhang Y, Li C-J, Highly Efficient Cross-Dehydrogenative-Coupling between Ethers and Active Methylene Compounds. Angew. Chem., Int. Ed., 2006; 45, 1949-1952.

[163] Yoo W-J, Correia CA, Zhang YLi C-J. The direct Csp3-H alkenylation with olefins would be more appealing, Synlett., 2009; 138-142.

[164] Li C-J. 2,3-Dichloro-5,6-dicyano-1,4-benzoquinone-Catalyzed Reactions Employing MnO2 as a Stoichiometric Oxidant. Acc. Chem. Res. 2009; 42, 335-344.

[165] Richter H, Mancheño OG. Dehydrogenative Functionalization of C(sp3)-H Bonds Adjacent to a Heteroatom Mediated by Oxoammonium Salts. Eur. J. Org. Chem. 2010; 4460-4467.

[166] Tsang ASK, Jensen P, Hook JM, Hashmi ASK, Todd MH. Standards for photoluminescence quantum yield measurements in solution. Pure Appl. Chem. 2011; 83, 655-665.

[167] Richter H, Rohlmann R, Mancheño OG. Catalyzed Selective Direct $\alpha$ - and $\gamma$-Alkylation of Aldehydes with Cyclic Benzyl Ethers by Using $\mathrm{T}^{+} \mathrm{BF}_{4}^{-}$in the Presence of an Inexpensive Organic Acid or Anhydride. Chem. Eur. J., 2011; 17, 11622-11627.

[168] Chen Y, Tian S-K. Decarboxylative Alkylation of $\beta$-Keto Acids with Isochromans under Oxidative Conditions, Chin. J. Chem., 2013; 31, 37-39. 
[169] Ghobrial M, Harhammer K, Mihovilovic MD, Schnürch M. Facile, solvent and ligand free iron catalyzed direct functionalization of N-protected tetrahydroisoquinolines and isochroman, Chem. Commun., 2010; 46, 88368838.

[170] Ghobrial M, Schnürch M, Mihovilovic MD. Direct Functionalization of (Un)protected Tetrahydroisoquinoline and Isochroman under Iron and Copper Catalysis: Two Metals, Two Mechanisms, J. Org. Chem., 2011; 76, 8781-8793.

[171] Park SJ, Price JR, Todd MH. Oxidative Arylation of Isochroman. J. Org. Chem., 2012; 77, 949-955.

[172] Schweitzer-Chaput B, Sud A, Pintér A, Dehn S, Schulze P, Klussmann M. Synergistic Effect of Ketone and Hydroperoxide in Brønsted Acid Catalyzed Oxidative Coupling Reactions. Angew. Chem, Int. Ed., 2013; 52, 1322813232.

[173] Qvortrup K, Rankic DA, MacMillan DWC. A General Strategy for Organocatalytic Activation of C-H Bonds via Photoredox Catalysis: Direct Arylation of Benzylic Ethers. J. Am. Chem. Soc., 2014; 136, 626-629.

[174] Muramatsu W, Nakano K. Organocatalytic Approach for C( $\left.\mathrm{sp}^{3}\right)-\mathrm{H}$ Bond Arylation, Alkylation, and Amidation of Isochromans under Facile Conditions. Org. Lett., 2014; 16, 2042-2045.

[175] Muramatsu W and Nakano K. Efficient C( $\left.\mathrm{sp}^{3}\right)-H$ Bond Functionalization of Isochroman by AZADOL Catalysis. Org. Lett., 2015; 17, 1549-1552.

[176] Dalko PI, Moisan L. In the Golden Age of Organocatalysis. Angew. Chem., Int. Ed., 2004; 43, 5138-5175.

[177] Volla CMR, Atodiresei I, Rueping M. Catalytic C-C Bond-Forming Multi-Component Cascade or Domino Reactions: Pushing the Boundaries of Complexity in Asymmetric Organocatalysis. Chem. Rev., 2014; 114, 2390-2431.

[178] Moyano A, Rios R. Asymmetric Organocatalytic Cyclization and Cycloaddition Reactions. Chem. Rev., 2011; 111, 4703-4832.

[179] Wei Y, Shi M. Recent advances in organocatalytic asymmetric Morita-Baylis-Hillman/aza-Morita-Baylis-Hillman reactions.Organocatalytic Carbon-Sulfur Bond-Forming Reactions. Chem. Rev., 2013; 113, 6659-6690.

[180] Chauhan P, Mahajan S, Enders D. Organocatalytic Carbon-Sulfur Bond-Forming Reactions, Chem. Rev., 2014; 114, 8807-8864.

[181] Zhu Y, Wang Q, Cornwall RG, Shi Y. Organocatalytic Asymmetric Epoxidation and Aziridination of Olefins and Their Synthetic Applications. Chem. Rev., 2014; 114, 8199-8256.

[182] Fang X, Wang C-J. Recent advances in asymmetric organocatalysis mediated by bifunctional amine-thioureas bearing multiple hydrogen-bonding donors. Chem. Commun., 2015; 51, 1185-1197.

[183] Wang C-J, Dong X-Q, Zhang Z-H, Xue Z-Y, Teng H-L. Highly anti-Selective Asymmetric Nitro-Mannich Reactions Catalyzed by Bifunctional Amine-Thiourea-Bearing Multiple Hydrogen-Bonding Donors. J. Am. Chem. Soc., 2008; 130, 8606-8607.

[184] Zhu Q, Lu Y. Stereocontrolled Creation of All-Carbon Quaternary Stereocenters by Organocatalytic Conjugate Addition of Oxindoles to Vinyl Sulfone. Angew. Chem., Int. Ed., 2010; 49, 7753-7756.

[185] Palomo C, Oiarbide M, Laso A. Recent Advances in the Catalytic Asymmetric Nitroaldol (Henry) Reaction. Eur. J. Org. Chem., 2007; 2561-2574.

[186] Zhang M-L, Yue D-F, Zhen-Hua Wang Z-H, Luo Y, Xu X-Y, Zhang X-M and Yuan W-C Organocatalytic asymmetric Henry reaction of $1 \mathrm{H}$-pyrrole-2,3-diones with bifunctional amine-thiourea catalysts bearing multiple hydrogenbond donors. Beilstein J. Org. Chem., 2016; 12, 295-300.

[187] Vona JA and Merker PC. Brominations Conducted with Pyridinium Bromide Perbromide, J. Org. Chem., 1949; $14(6), 1048-1050$

[188] Djerassi C and Scholz CR. Brominations Conducted with Pyridinium Bromide Perbromide, J. Am. Chem. Soc., 1948; 70, 417.

[189] Xiang S-K, Zhang B, Zhang L-H, Cui Y and Jiao N, Morpholine catalyzed direct C3 alkenylation of indoles with $\alpha, \beta$ unsaturated aldehydes, Chem. Commun., 2011;47, 8097.

[190] Song X, Song A, Zhang F, Li H-X and Wang W. Direct stereoselective $\alpha$-arylation of unmodified enals using an organocatalytic cross-coupling-like reaction. Nat. Commun., 2011; 2, 524. 
[191] Hu Y, Ma Y, Sun R, Yu X, Xie H and Wang W Amine-Catalyzed Highly Regioselective and Stereoselective C(sp2)C(sp2) Cross-Coupling of Naphthols with trans- $\alpha, \beta$-Unsaturated Aldehydes. Chemistry - An Asian Journal, 2015; 10(9), 1859-1863.

[192] Meninno S and Lattanzi A. Asymmetric organocatalysis mediated by $\alpha, \alpha$-L-diaryl prolinols: recent advances. Chem. Commun., 2013; 49, 3821

[193] Jensen KL, Dickmeiss G, Jiang Albrecht H, and Jorgensen KA. The diarylprolinol silyl ether system: a general organocatalyst. Acc. Chem. Res., 2012; 45, 248

[194] Mukherjee S, Yang JW, Ho-mann S and List B. Asymmetric enamine catalysis. Chem. Rev., 2007; 107, 5471.

[195] Hu Y, Jun L, Lu L, Ma H and Yu X. Stereoselective $\alpha$-indolylation of enals via an organocatalytic formal crosscoupling with indoles. Org. Biomol. Chem., 2015; 13, 8869-8874.

[196] Cozzi PG, Benfatti F and Zoli L. Organocatalytic asymmetric alkylation of aldehydes by S(N)1-type reaction of alcohols. Angew. Chem., Int. Ed., 2009; 48, 1313.

[197] Mayr H, Kempf B and Ofial AR. $\pi$-Nucleophilicity in Carbon-Carbon Bond-Forming Reactions, Acc. Chem. Res., $2003 ; 36,66$

[198] MacMillan DWC. The advent and development of organocatalysis. Nature, 2008; 455, 304.

[199] Tu W, Lei L and Floreancig PE. Diastereoselective Tetrahydropyrone Synthesis through TransitionMetal-Free Oxidative Carbon-Hydrogen Bond Activation. Angew. Chem., Int. Ed., 2008; 47, 4184

[200] Xu Y-C, Kohlman DT, Liang SX and Erikkson C. Oxidative C-C Bond Coupling of Naphthopyran Induced by DDQ: Stereocontrolled Total Synthesis of Deoxyfrenolicin. Org. Lett., 1999; 1, 1599

[201] Zhang Y and Li C-J. Highly efficient cross-dehydrogenative-coupling between ethers and active methylene compounds. Angew. Chem., Int. Ed., 2006; 45, 1949

[202] Zhang Y and Li C-J. DDQ-Mediated Direct Cross-Dehydrogenative-Coupling (CDC) between Benzyl Ethers and Simple Ketones. J. Am. Chem. Soc., 2006; 128, 4242.

[203] Sud A, Sureshkumar D and Klussmann M. Oxidative coupling of amines and ketones by combined vanadium- and organocatalysis. Chem. Commun., 2009; 3169.

[204] Fu PP and Harvey RG. Dehydrogenation of polycyclic hydroaromatic compounds. Chem. Rev., 1978; 78, 317.

[205] Snider BA. Manganese(III)-Based Oxidative Free-Radical Cyclizations. Chem. Rev., 1996; 96, 339.

[206] Lelais G and MacMillan DWC. Modern Strategies in Organic Catalysis: The Advent and Development of Iminium Activation. Aldrichimica Acta, 2006; 39, 79.

[207] Mielgo and C. Palomo, $\alpha, \alpha$-Diarylprolinol Ethers: New Tools for Functionalization of Carbonyl Compounds, Chem. Asian J., 2008, 3, 922.

[208] Cabrera S, Reyes E, Aleman J, Milelli A, Kobbelgaard S. and Jprgensen KA, Organocatalytic asymmetric synthesis of alpha,alpha-disubstituted alpha-amino acids and derivatives, J. Am. Chem. Soc., 2008; 130, 12031

[209] Cabrera S., Aleman J., Bolze P., Bertelsen S. and Jprgensen K. A., 2008, An unexpected organocatalytic asymmetric tandem Michael/Morita-Baylis-Hillman reaction, Angew. Chem., Int. Ed., 47, 121

[210] Franke PT, Richter B and Jprgensen K. A. Organocatalytic asymmetric synthesis of functionalized 3,4dihydropyran derivatives Chemistry. Chem. Eur. J., 2008; 14, 6317

[211] Bertelsen S, Johansen RL and Jprgensen KA. Controlling the formation of 1 out of 64 stereoisomers using organocatalysis. Chem. Commun., 2008; 3016.

[212] Hayashi Y, Pkano T, Aratake S and Hazelard D. Catalytic stereoselective benzylic C-H functionalizations by oxidative C-H activation and organocatalysis. Angew. Chem., Int. Ed., 2007; 46, 4922.

[213] Enders D., Hutt M. R. M. l, Grondal C. and Raabe G, Control of four stereocentres in a triple cascade organocatalytic reaction. Nature, 2006; 441, 861.

[214] Gotoh H, Masui R, Ogino H, Shoji M and Hayashi Y. Enantioselective ene reaction of cyclopentadiene and alpha,beta-enals catalyzed by a diphenylprolinol silyl ether. Angew. Chem., Int. Ed., 2006; 45, 6853.

[215] Zhao Y-L, Wang Y, Luo Y-C, Fu X-Z, Xu P-F, Asymmetric C-H functionalization involving organocatalysis. Tetrahedron letters, 2015; 56, 3703-3714. 
[216] Benfatti F, Capdevila MG, Zoli L, Benedetto E and Cozzi PG. Catalytic stereoselective benzylic C-H functionalizations by oxidative C-H activation and organocatalysis. Chem. Commun., 2009; 5919-5921.

[217] Zhang B, Xiang S-K, Zhang L-H, Cui Y, and Jiao N, Organocatalytic Asymmetric Intermolecular Dehydrogenative $\alpha$-Alkylation of Aldehydes Using Molecular Oxygen as Oxidant. Org. Lett., 2011; 13(19), 5212-5215.

[218] Jprgensen KA. Asymmetric Friedel-Crafts Reactions: Catalytic Enantioselective Addition of Aromatic and Heteroaromatic C-H Bonds to Activated Alkenes, Carbonyl Compounds, and Imines. Synthesis, 2003; 1117.

[219] Bandini M, Melloni A, Umani-Ronchi A. New catalytic approaches in the stereoselective Friedel-Crafts alkylation reaction. Angew. Chem., Int. Ed., 2004,43, 550.

[220] Uraguchi D, Sorimachi K, and Terada M. Organocatalytic Asymmetric Direct Alkylation of $\alpha$-Diazoester via C-H Bond Cleavage, J. AM. CHEM. SOC., 2005; 127, 9360-9361.

[221] Sun C-L, Li B-J \& Shi Z. Pd-catalyzed oxidative coupling with organometallic reagents via C-H activation, J. Chem. Commun., 2010; 46, 677-685.

[222] Sun C-L, Li H, Yu D-G, Yu M, Zhou X, Lu X-Y, Huang K, Zheng S-F, Li B-J and Shi Z-J, 2010, An efficient organocatalytic method for constructing biaryls through aromatic C-H activation, Nat. Chem., 2(12) 1044-1049.,

[223] Shepherd NE, Tanabe H, Xu Y, Matsunaga S, Shibasaki M, Direct Catalytic Asymmetric Vinylogous Mannich-Type and Michael Reactions of an $\alpha, \beta$-Unsaturated $\gamma$-Butyrolactam under Dinuclear Nickel Catalysis, J. Am. Chem. Soc., 2010; 132, 3666.

[224] Choudhury AR, Mukherjee S. Organocatalytic asymmetric direct vinylogous Michael addition of $\alpha, \beta$-unsaturated $\gamma$-butyrolactam to nitroolefins, Org. Biomol. Chem., 2012; 10, 7313.

[225] Feng X, Cui H, Xu S, Wu, L, Chen Y. Organocatalytic Direct Vinylogous Michael Addition of a,b-Unsaturated gButyrolactam to a,b-Unsaturated Aldehydes and an Illustration to Scaffold Diversity Synthesis, Chem. Eur. J. 2010; 16, 10309.

[226] Zhang Y, Shao Y-L, Xu H, Wang W. Organocatalytic Direct Asymmetric Vinylogous Michael Reaction of an $\alpha, \beta-$ Unsaturated $\gamma$-Butyrolactam with Enones, J. Org. Chem., 2011,76, 1472.

[227] Huang H, Jin Z, Zhu K, Liang XYe, Highly diastereo- and enantioselective synthesis of 5-substituted 3-pyrrolidin2-ones: vinylogous Michael addition under multifunctional catalysis, J. Angew.Chem., Int. Ed., 2011; 50, 3232.

[228] Lin L, Zhang J, Ma X, Fu X, Wang R. Bifunctional 3,3'-Phz-BINOL-Mg Catalyzed Direct Asymmetric Vinylogous Michael Addition of $\alpha, \beta$-Unsaturated $\gamma$-Butyrolactam. Org. Lett., 2011; 13, 6410.

[229] Yang Y, Dong S, Liu X, Lin L, Feng X. Chiral guanidine-catalyzed asymmetric direct vinylogous Michael reaction of $\alpha, \beta$-unsaturated $\gamma$-butyrolactams with alkylidene malonates. Chem. Commun., 2012; 48, 5040.

[230] Zhu J-L, Zhang Y, Liu C, Zheng A, Wang W. Insights into the Dual Activation Mechanism Involving Bifunctional Cinchona Alkaloid Thiourea Organocatalysts: An NMR and DFT Study. J. Org. Chem. 2012; 77, 9813.

[231] Ma Y, Zhang G, Zhang J, Yang D, and Wang R Organocatalyzed Asymmetric Oxidative Coupling of $\alpha$-Csp3-H of Tertiary Amines to $\alpha, \beta$-Unsaturated $\gamma$-Butyrolactam: Synthesis of MBH-Type Products. Org. Lett., 2014; 16, 53585361.

[232] Li Z, Wei D, Wang Y, Zhu Y, Tang M. DFT Study on the Mechanisms and Stereoselectivities of the [4+2] Cycloadditions of Enals and Chalcones Catalyzed by N-Heterocyclic Carbene. J. Org. Chem., 2014; 79, 3069-3078. 